\title{
The contributions of fronts, lows and thunderstorms to southern Australian rainfall
}

\author{
Acacia S. Pepler ${ }^{1}\left[\right.$ ] Andrew J. Dowdy ${ }^{1} \cdot$ Peter van Rensch ${ }^{1} \cdot$ Irina Rudeva ${ }^{1,2} \cdot$ Jennifer L. Catto ${ }^{3} \cdot$ Pandora Hope $^{1}$
}

Received: 28 January 2020 / Accepted: 13 June 2020 / Published online: 17 June 2020

(c) The Author(s) 2020

\begin{abstract}
A systematic analysis of the main weather types influencing southern Australian rainfall is presented for the period 19792015. This incorporates two multi-method datasets of cold fronts and low pressure systems, which indicate the more robust fronts and lows as distinguished from the weaker and less impactful events that are often indicated only by a single method. The front and low pressure system datasets are then combined with a dataset of environmental conditions associated with thunderstorms, as well as datasets of warm fronts and high pressure systems. The results demonstrate that these weather types collectively account for about $86 \%$ of days and more than $98 \%$ of rainfall in Australia south of $25^{\circ} \mathrm{S}$. We also show how the key rain-bearing weather systems vary throughout the year and for different regions, with the co-occurrence of simultaneous lows, fronts and thunderstorm conditions particularly important during the spring and summer months in southeast Australia.
\end{abstract}

Keywords Cyclone $\cdot$ Front $\cdot$ Thunderstorm $\cdot$ Rainfall $\cdot$ Reanalysis

\section{Introduction}

A number of studies in recent years have used reanalysis data to associate global and regional rainfall with specific weather systems, including fronts (Catto et al. 2012, 2015; Catto and Pfahl 2013; Blázquez and Solman 2017; Raut et al. 2017) and low pressure systems (Dare et al. 2012; Pfahl and Wernli 2012; Hawcroft et al. 2012; Lavender and Abbs 2013). However, recent research has highlighted that, rather than analysing synoptic systems in isolation, for extreme rainfall and wind the co-occurrence of fronts and lows as well as the interaction of these events with smallerscale convective systems such as thunderstorms becomes increasingly important (Dowdy and Catto 2017). Dowdy and Catto (2017), hereafter 'DC17', referred to cases with more than one of these weather systems in a given locations as "concurrent" events, and showed that while they occur relatively infrequently they are disproportionately likely to cause extreme wind and extreme rainfall. In many areas of

Acacia S. Pepler

acacia.pepler@bom.gov.au

Bureau of Meteorology, Melbourne, Australia

2 University of Melbourne, Melbourne, Australia

3 University of Exeter, Exeter, UK the globe concurrent storm types are responsible for more extreme events than any weather system in isolation. For this reason, it is useful to understand the interactions between different weather systems when explaining the drivers of regional rainfall.

Southern Australian rainfall is influenced by a large number of weather systems including extratropical and subtropical cyclones, low pressure troughs, thunderstorms, cold and warm fronts, and transient and blocking high pressure systems (Sturman and Tapper 1996). Several previous studies have investigated the contribution of these weather systems individually to Australian rainfall as well as how they may have changed over recent decades, including for low pressure systems (Pepler et al. 2014a; Lavender and Abbs 2013; Ng et al. 2015; Qi et al. 2006), high pressure systems (Pepler et al. 2019b), and northwest cloud bands (Reid et al. 2019). In addition, there have been several studies that attempt to attribute all rainfall in a given region to a larger number of synoptic types using either manual classification or selforganising maps, including Victoria in southeast Australia (Wright 1989; Risbey et al. 2013; Verdon-Kidd and Kiem 2009), southwestern Western Australia (Pook et al. 2011), and tropical Australia (Moron et al. 2019). However, in each of these studies any rain event can be associated with at most one weather system, which does not allow for an assessment of how they may interact. 
Southern Australia is a region that has been experiencing long-term declines in cool season rainfall, which has been attributed to a large number of factors including an expansion of the Hadley cell and strengthening subtropical ridge (Timbal and Drosdowsky 2013), a decrease in the rainfall from fronts and cyclones (Hope et al. 2006; Risbey et al. 2013), and an increase in the frequency of anticyclones (Pepler et al. 2019b). At the same time, parts of southeastern Australia have seen an increase in the frequency of thunderstorm conditions (Dowdy 2020). Meanwhile, global climate models project a continued decline in rainfall in southern Australia into the future, driven by large-scale circulation changes (Hope et al. 2015). Future changes are expected to differ between different types of weather systems, with some systems likely to be better portrayed by coarse global models than others. Consequently, in order to better understand past and future trends in rainfall associated with weather systems, it is important to better quantify the influence each weather system and interactions between them have on rainfall in the current climate, and how that may differ across Australia. This paper builds on previous work including DC17 to present a new dataset of the main weather types that influence southern Australian rainfall. This dataset incorporates several novel developments including:

- The combination of two distinct methods for identifying low pressure systems and two methods for identifying cold fronts from reanalysis data. This allows us to distinguish those cold fronts or low pressure systems that are consistently identified across methods from weaker or less certain systems. We can thus account for the uncertainties associated with any single automated identification method and more clearly identify those weather systems more likely to produce significant rainfall.

- Environmental conditions associated with thunderstorm activity are used in combination with the fronts and lows datasets to extend the compound event analysis back to 1979.

- A recently-developed database of anticyclones in Australia, as these are important for dry weather and have contributed to long-term rainfall trends in parts of southeast Australia (Timbal and Drosdowsky 2013; Pepler et al. 2019b)

This paper first presents the different datasets of cyclones, fronts, thunderstorms and anticyclones, and shows a new way of combining different cyclone and front methods to better capture the systems most likely to cause rainfall. We then show the contributions of each weather system and their interactions to both total rainfall and heavy rain days across southern Australia, highlighting the spatial and seasonal variability. This new dataset will then be used in future work to help better understand the contributions different weather systems and their interactions make to Australian rainfall variability and trends in recent decades.

\section{Methods and data}

The weather types dataset is based on the $0.75^{\circ}$ ERA-Interim reanalysis (Dee et al. 2011) between 1979 and 2015, for general consistency with the compound event datasets developed in DC17 for the period 2005-2015, but extending the analysis to 1979 to cover a longer time period for analyses. ERA-Interim is one of the most widely-used reanalyses for studies of fronts and cyclones around the globe (Catto et al. 2012; Neu et al. 2013; Rudeva and Simmonds 2015), and compares favourably with other reanalyses and manual cyclone databases (Pepler et al. 2018; Di Luca et al. 2015; Tilinina et al. 2013; Hodges et al. 2011). This is also the reanalysis used in developing a recent database of thunderstorm environments for Australia (Dowdy 2020). ERA-Interim has since been replaced by the newer high-resolution dataset ERA5 (C3S 2017), which was not available when our initial cyclone, front and thunderstorm datasets were produced, but is expected to give broadly similar results based on initial tests using the University of Melbourne cyclone tracking method (not shown).

\subsection{Cyclones (low pressure systems)}

There are numerous different automated methods for identifying and tracking cyclones in gridded pressure data (Neu et al. 2013). While different methods generally agree on the identification/frequency of intense cyclones, there can be larger uncertainties in identifying weaker systems. These differences can be sufficiently large that they change the observed interannual variability of cyclone activity and relationships with climate drivers such as the El Niño-Southern Oscillation (Pepler et al. 2015). For this reason, we use two different methods of identifying cyclones in order to increase the robustness of the dataset.

An earlier global study of concurrent storm types by DC17 applied the Wernli and Schwierz (2006) cyclone identification and tracking method to ERA-Interim 6-hourly sea level pressure (SLP) data (WS06). This cyclone method identifies closed low pressure systems as contiguous areas where SLP is at least $0.5 \mathrm{hPa}$ below the surrounding grid cells. This method has been applied globally to link cyclones with extreme precipitation (Pfahl and Wernli 2012), and has the advantage of being able to identify the appropriate region of influence for cyclones of a wide range of shapes, rather than assuming a circular system. In addition, by searching for the outermost closed contour this method can easily handle systems with multiple centres, which can be split into multiple cyclones by methods that search for 
cyclone centres. However, this method may also identify large but weak areas of low pressure, such as associated with an extended surface trough, that may not be considered "cyclones" by other methods.

For the current paper, we build on the dataset from DC17 by adding cyclones identified using the University of Melbourne (UM) cyclone identification and tracking method (Murray and Simmonds 1991; Simmonds et al. 1999; Simmonds and Keay 2000), which has been widely used for cyclones in Australia and globally (Jones and Simmonds 1993; Allen et al. 2010; Pepler et al. 2015; Papritz et al. 2014). This method first re-grids the 6-hourly ERA-Interim SLP data onto a polar stereographic grid before searching for maxima in the Laplacian of pressure. The method then searches for an associated minimum in the SLP pressure field and returns the point location of the cyclone centre. We retain only closed circulations where the average Laplacian over a $5^{\circ}$ radius is at least $0.15 \mathrm{hPa}(\mathrm{deg} \text {. lat })^{-2}$. This is a weaker intensity criterion than used in recent studies employing this same method for severe cyclones in eastern Australia (Pepler et al. 2015), but is consistent with that applied in the original studies and allows for a better combination with the Wernli and Schwierz (2006) dataset.

Both these cyclone identification methods have been applied solely to SLP, which is the level most likely to be associated with heavy rainfall when tracking on a single level (Pepler and Dowdy 2020). However, many of the most impactful cyclones in southern Australia have a stronger signature in the upper levels of the atmosphere, and may have only weak cyclone development on the surface (Dowdy et al. 2011; Risbey et al. 2013). The use of weak intensity thresholds for both cyclone methods means the majority of these are expected to be identified when they have surface impacts, but it is possible that some cut-off lows may be misclassified as cold fronts or thunderstorms at the surface.

\subsection{Fronts}

As with cyclones there are a large number of different methods for identifying fronts from gridded reanalysis data. The majority of these approaches search for a change in the air mass by identifying a gradient in temperature and/or humidity, with the fronts identified being sensitive to a range of choices in applying the method (Thomas and Schultz 2019a, b). Cold fronts can also be identified by a change in wind direction (Simmonds et al. 2012; Rudeva and Simmonds 2015; Bitsa et al. 2019), from northwesterly to southwesterly in the Southern Hemisphere.

Both of the front detection approaches used in this paper performed well in comparison to a manually developed front database in southwestern Australia (Hope et al. 2014). However, a study by Schemm et al. (2015) demonstrated that identification of fronts using a gradient in equivalent potential temperature may lead to a large number of events indicated in areas of high temperature and moisture gradients (e.g., along coast lines), which would not be picked up by a wind-based method. Hence, a combination of two approaches to identify cold fronts which requires both a temperature gradient and a wind shift may help select significant fronts that are more likely to be associated with rainfall and other impacts.

DC17 applied the front identification method of Berry et al. (2011) on $0.75^{\circ}$ ERA-Interim data. This method uses a thermal front parameter (TFP), based on the $850 \mathrm{hPa}$ wet bulb potential temperature, $\theta_{\mathrm{w}}$, as shown in Eq. (1). The method firstly selects regions where the TFP is above a threshold value $\left(-0.5 \mathrm{~K}(100 \mathrm{~km})^{-2}\right)$, then identifies fronts from points within these regions where the gradient of TFP is zero. This method allows both warm and cold fronts to be identified, and can identify fronts with a range of shapes and orientations. Warm fronts identified using the TFP are considered separately as they are less likely to produce significant rainfall in Australia (Catto et al. 2012) and are thus frequently not drawn on synoptic charts.

$\operatorname{TFP}\left(\theta_{w}\right)=-\nabla\left|\nabla \theta_{w}\right| \cdot\left(\frac{\nabla \theta_{w}}{\left|\nabla \theta_{w}\right|}\right)$

In comparison, the Simmonds et al. (2012) approach (WND) compares two consecutive 6-hourly analyses of $10 \mathrm{~m}$ wind, and identifies a front when the horizontal wind shifts in direction from the northwest to southwest quadrant and the meridional wind increases by at least $2 \mathrm{~m} \mathrm{~s}^{-1}$ over $6 \mathrm{~h}$. Objective features are then identified, with the easternmost edge of the frontal region identified as a front. Although Simmonds et al. (2012) associated the wind change between $t$ and $t+6 h$ to fronts at time $t$, we shift this to time $t+6 h$ to better match the structures in other fields as well as the Berry et al. (2011) fronts, consistent with Papritz et al. (2014). This method was applied to ERA-Interim data at a global $1.5^{\circ}$ resolution by Rudeva and Simmonds (2015) and Schemm et al. (2015), and we retain only those fronts that have a length of at least 2 grid cells (i.e., $3^{\circ}$ ). This method is able to identify meridionally elongated cold fronts that can cause significant impacts in southern Australia (Hope et al. 2014), but cannot identify warm fronts or fronts that are more zonally aligned.

\subsection{Thunderstorms}

DC17 employed observed lightning datasets to identify areas with thunderstorm activity, restricting their results to the recent period 2005-2015. To extend this to a longer period, a recent study for Australia used lightning observations to identify environmental conditions associated with thunderstorm activity from the ERA-Interim reanalysis data back to 
1979 (Dowdy 2020). The environmental conditions method extracts convective available potential energy (CAPE; using the most unstable level based on maximum equivalent potential temperature) and bulk wind shear from 0 to $6 \mathrm{~km}$ (S06) from ERA-Interim. S06 and CAPE are bilinearly regridded to a $0.05^{\circ}$ resolution and used to calculate the thunderstorm parameter $\left(\mathrm{CAPE}^{*} \mathrm{~S} 6^{1.67}\right)$. These are the same input variables used in previous similar approaches, including Brooks et al. (2003) and Allen and Karoly (2014).

The thunderstorm parameter is then compared to two lightning products to identify local thresholds that give the same annual thunderstorm frequency as observed. The first lightning dataset is from the commercial provider Global Position and Tracking Systems Pty. Ltd. Australia, which has coverage throughout Australia, which is combined with the World Wide Lightning Location Network which has global coverage (Hutchins et al. 2013; Virts et al. 2013). Both of the lightning datasets are based on the time of arrival of the electromagnetic disturbance propagating away from the lightning discharge as recorded at a network of groundbased radio receivers (Cummins and Murphy 2009) and contain information about the time and location of individual lightning strokes. The appropriate thunderstorm parameter thresholds were calculated for each location for the period 2005-2015 based on the period of available lightning data, then subsequently applied back to 1979 .

To combine the thunderstorm dataset with the other $0.75^{\circ}$ resolution datasets it is then converted to a $0.75^{\circ}$ resolution, where a grid point is considered to be influenced by thunderstorms if any point within the $0.75^{\circ} \times 0.75^{\circ}$ area exceeds the local thunderstorm environment threshold. For further details on this environmental approach, see Brooks et al. (2003), Allen and Karoly (2014) and Dowdy (2020).

\subsection{Anticyclones (high pressure systems)}

To supplement the rain-bearing synoptic types and more fully account for the main weather systems affecting Australia, we also incorporate a dataset of anticyclones from Pepler et al. (2019a,b). This applied the same UM tracking scheme described in Sect. 2.2 to ERA-Interim SLP, but instead searched for minima in the Laplacian and a local SLP maximum. To account for the larger spatial scale of anticyclones, the Laplacian is required to be below $-0.075 \mathrm{hPa}(\mathrm{deg} \text {. lat })^{-2}$ averaged for a $10^{\circ}$ radius around the anticyclone centre, and areas within a $10^{\circ}$ radius of an anticyclone centre are considered to be affected by an anticyclone, consistent with anticyclone composites for Australia in Pepler et al. (2019b). For consistency with cyclones, anticyclones have been identified using only SLP data, allowing us to identify mobile anticyclones as well as the persistent anticyclonic anomalies in SLP that may be associated in some cases with upper-level anticyclones and blocking (Liu et al. 2017; Pook et al. 2013). Upper air data would help identify deep, warm-cored anticyclonessuch as blocking highs - and their interaction with upper air lows including cut-off lows. This is beyond the scope of this study, but might be worthy of further investigation in subsequent studies.

Anticyclones have a strong local effect of suppressing rainfall; however, they can generate strong non-local effects linked to rainfall. For example, anticyclones in the Tasman Sea can be associated with the development of strong onshore flow that and significant rainfall on the east coast (Pepler et al. 2019b). This is particularly true for persistent "blocking" anticyclones, which are strongly associated with rainfall in parts of southeastern Australia during the spring (Pook et al. 2013) and may be less evident at the surface than at higher levels. Anticyclones can also affect the broader circulation resulting in non-local increases in rainfall in areas more than $10^{\circ}$ from the anticyclone centre (Rehman et al. 2019), particularly in cases where the anticyclone interacts with cyclones or other weather systems (Hopkins and Holland 1997; Cao et al. 2019), but this will not be detected in our dataset. Interactions between upper air systems including between an upper anticyclone and a cut-off low can also contribute to rainfall generation in the absence of a surface signal (Wright 1989).

\subsection{Rainfall}

The contributions of each weather type to Australian rainfall are initially analysed using the Australian Water Availability Project (AWAP) rainfall dataset (Jones et al. 2009). This is a $0.05^{\circ}$ resolution daily gridded rainfall analysis for Australia based on rain gauge data from 1900 to present, and is the most widely used dataset for studying Australian rainfall variability.

As well as daily gridded rainfall, we use 6-hourly rainfall observations from two sources: the new $12 \mathrm{~km}$ Bureau of Meteorology Atmospheric high-resolution Regional Reanalysis for Australia (BARRA; Su et al. 2019) over 1990-2015 as well as that from all Bureau of Meteorology gauges with hourly rainfall data for at least 10 years between 1979 and 2015. While reanalyses offer the advantage of gridded rainfall that is more spatially and temporally consistent than the more sporadic gauge datasets, the reliance on model-generated rainfall can result in a range of errors including an overestimation of wet days and an underestimation of extreme rainfall (Alexander et al. 2020). However, BARRA has been found to compare well with the AWAP reanalysis on a daily basis, particularly for extreme rainfall (Acharya et al. 2019), and provides an additional source of subdaily information to supplement the gauge data. 


\section{A combined weather types dataset}

The different datasets of cyclones, fronts, thunderstorms, and anticyclones described above are then combined into a single dataset of weather types. First, the two cyclone and two front methods are each combined to make more robust datasets of cyclones and fronts that are common to two independent methods, which allows us better to identify those associated with significant rainfall. These are then combined with the thunderstorm datasets to identify seven different weather types that consider the interaction between co-occurring events, as per DC17. Finally, the full weather type dataset is combined with the rainfall datasets to identify the relationship of each weather type with southern Australian rainfall.

\subsection{The combined cyclone dataset}

We first combine the two distinct cyclone datasets to identify those cyclones that are found using both methods. To do so, each unique cyclone area from WS06 is assessed against the UM cyclone centre dataset to check if a cyclone centre is contained within the cyclone area. These cyclones are considered "Confirmed cyclones", as they were identified by both methods, while areas that do not contain a UM cyclone centre are considered "Unconfirmed events". As there is no perfect cyclone method, the terms confirmed and unconfirmed are not intended to indicate whether a cyclone is "real" or not, merely the level of agreement between the two methods. Areas where a UM cyclone centre is located within a $5^{\circ}$ radius but there is no corresponding WS06 cyclone area are also considered "Unconfirmed events".

Figure 1 shows the percentage of 6-hourly observations influenced by a cyclone area that is confirmed by both methods (left), in comparison to areas where only one method identifies a cyclone (middle and right). Both methods were developed for application outside the tropics, and there is generally strong agreement between the two cyclone identification methods south of about $25^{\circ} \mathrm{S}$ in both seasons, with both methods detecting the main storm track to the south of Australia, as well as the area of high cyclone frequency in the Tasman Sea.

Both cyclone methods identify relatively few cyclones in northern Australia during the cool season, and a large frequency of cyclones in northwestern Australia during the warm season, consistent with the high frequency of cyclones and tropical depressions (Lavender and Abbs 2013). However, there is also considerable uncertainty between cyclone methods in this region, with large numbers of observations where a cyclone is detected by only one method (Fig. 1e, f). Each cyclone identification method could also be detecting a variety of other weather systems that may not produce substantial rainfall, including the semi-stationary West Coast Trough (Kepert and Smith 1992), the monsoon trough, and the Pilbara heat low (Sturman and Tapper 1996).

To associate cyclones with rainfall, we then add an additional $5^{\circ}$ area of influence beyond the definite (or (a) MJJASO: Confirmed cyclones

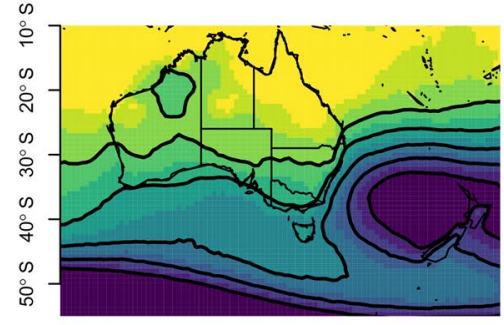

(d) NDJFMA: Confirmed cyclones

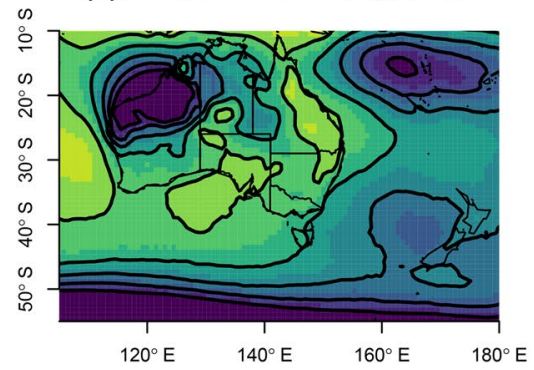

(b) MJJASO: Unconfirmed WS06 cyclones

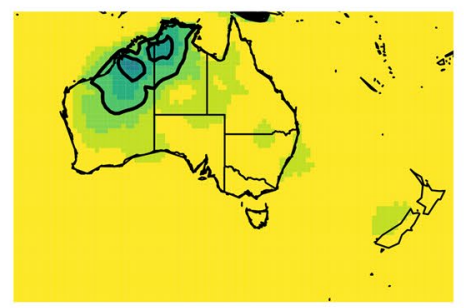

(e) NDJFMA: Unconfirmed WS06 cyclones

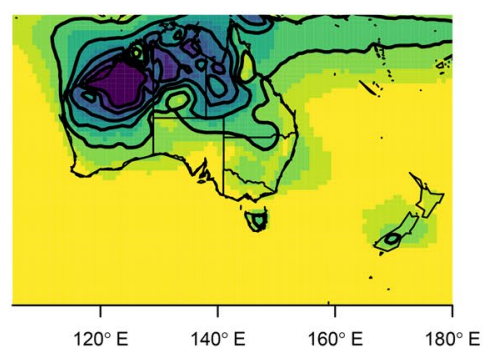

(c) MJJASO: Unconfirmed UM cyclones
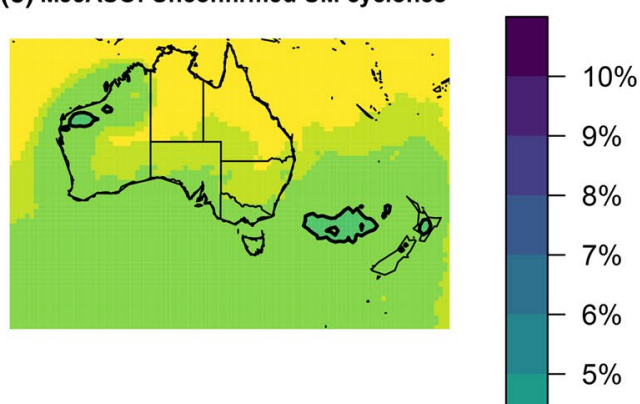

(f) NDJFMA: Unconfirmed UM cyclones

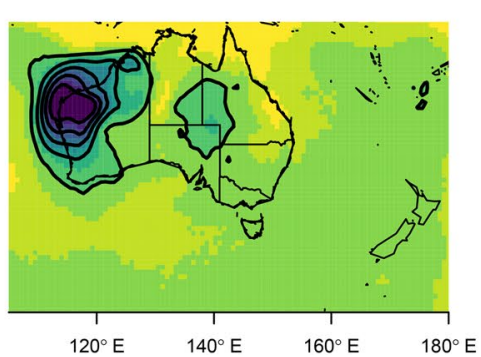

Fig. 1 Percentage of 6-hourly observations influenced by a cyclone, 1979-2015, in the cool season (May-October, top) and warm season (November-April, bottom). (Left) confirmed cyclones. (Middle) cyclones identified using the WS06 method but not the UM method. (Right) cyclones identified using the UM method but not the WS06 method. Black contours are shown every $2 \%$ 
unconfirmed) cyclone region. This is slightly larger than the $3^{\circ}$ radius used in $\mathrm{DC} 17$ for examining the more intense rainfall events, but better matches the full region influenced by rainfall in cyclone composites for southeast Australia (e.g. Figure 7a in Pepler and Dowdy 2020). In the case of unconfirmed $\mathrm{UM}$ cyclones, this $5^{\circ}$ region is added to the $5^{\circ}$ cyclone area used for Fig. 1, for a $10^{\circ}$ total radius of influence. This is similar to the radius of $10-12^{\circ}$ from the cyclone centre used for attributing rain to cyclones by Hawcroft et al. (2012) and the $\sim 10^{\circ}$ region with rain from cyclones in (Pepler et al. 2018).

It is important to note that we have used a constant region in degrees of latitude/longitude to identify the area of influence of each weather system, for simplicity and consistency with previous studies e.g. DC17. This means that a given weather system will be influencing a smaller spatial region in the south of the domain than it does in the north. However, the frequency of undefined events is no higher in Tasmania than it is elsewhere in Australia (Sect. 3.4), suggesting our regions of influence are sufficiently broad to identify the majority of rainfall associated with a given weather system at all our latitudes of interest. This effect becomes more significant for polar regions, which are not included in this study.

Figure 2 shows the average rainfall anomaly on cyclone days compared to the mean rainfall across all days. Days with a confirmed cyclone are more likely to be associated with rainfall than cyclones identified using only one method, with the average rainfall on Confirmed cyclone days double the average daily rainfall for all days. Averaged across the country, $28 \%$ of confirmed cyclone days have rainfall of at least $1 \mathrm{~mm}$, double the climatological likelihood of rainfall across all days (14\%) and substantially higher than unconfirmed WS06 days (18\%) or unconfirmed UM days (17\%). Averaged across southern Australia (south of $25^{\circ} \mathrm{S}$ ), for a given location $20 \%$ of days are influenced by a confirmed cyclone, but these days contribute on average $46 \%$ of the annual rainfall total (Table 1). Unconfirmed cyclones make a smaller contribution to rainfall, noting that unconfirmed cyclones may co-occur with other weather types.

While confirmed cyclones make a similar contribution to rainfall in northern Australia, there is also a large number of unconfirmed WS06 cyclones in this region, which make a lower contribution to total rainfall than confirmed systems (Table 1). While these results suggest the confirmed cyclone dataset improves on each individual cyclone dataset for detecting rainbearing lows in the tropics, there are larger uncertainties in northern Australia than southern Australia including the potential for both methods to miss small-sized systems such as some tropical cyclones and tropical depressions as both methods were developed to identify extratropical systems. Consequently, the primary focus of this paper is on southern Australia and the weather systems that are associated with rainfall in this region.

\subsection{The confirmed cold front dataset}

We similarly combine the two cold front datasets to identify cold fronts where a wind shift is combined with a wet bulb temperature change, as significant fronts are expected to satisfy both criteria (Hope et al. 2014). First, the WND dataset and the cold fronts identified using TFP are each expanded to a grid of frontal area, with a region considered

Table 1 Annual average proportion of days with a cyclone present, and proportion of rainfall record on days with a cyclone present, for northern (north of $25^{\circ} \mathrm{S}$ ) and southern (south of $25^{\circ} \mathrm{S}$ )

\begin{tabular}{llllll}
\hline & \multicolumn{2}{l}{ Northern Australia } & & \multicolumn{2}{l}{ Southern Australia } \\
\cline { 2 - 3 } \cline { 6 - 6 } \cline { 6 - 7 } \% of days & \% of rain & & \% of days & \% of rain \\
\hline Confirmed cyclones & 21 & 49 & & 20 & 46 \\
WS06 only & 20 & 24 & & 10 & 13 \\
UM only & 3 & 3 & & 6 & 6 \\
\hline
\end{tabular}

(a) Confirmed cyclones

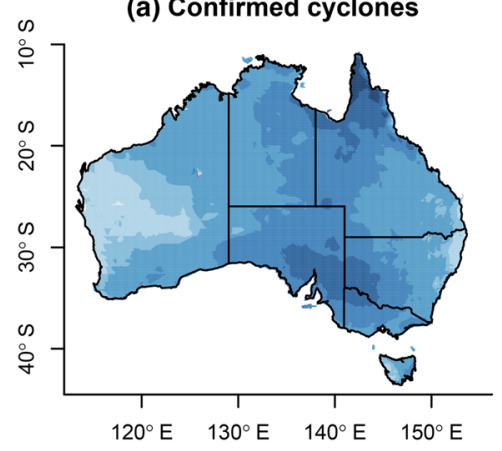

(b) Unconfirmed WS06 cyclones

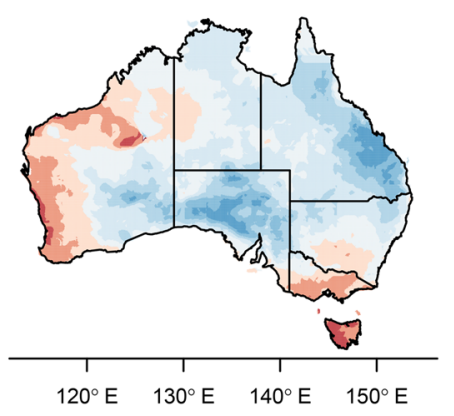

(c) Unconfirmed UM cyclones

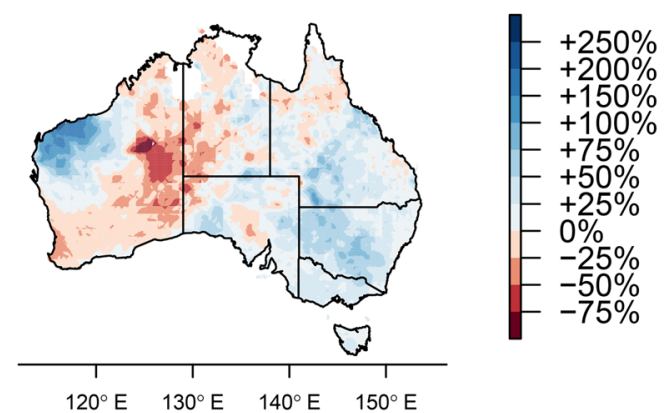

Fig. 2 Annual percentage difference between the average rainfall recorded on a day with a cyclone, compared to the average daily rainfall across all days, 1979-2015. (Left) confirmed cyclones. (Middle) cyclones identified using the WS06 method but not the UM method. (Right) cyclones identified using the UM method but not the WSO6 method 
to be influenced by a front if it is within a $5^{\circ}$ radius of the front. This is a larger region than used by $\mathrm{DC} 17$ for their focus on more intense rainfall amounts, but better accounts for the full area of potential pre- and post-frontal rainfall as well as the movement of the front location throughout the $6 \mathrm{~h}$ period, as this study aims to consider all rainfall intensities. As with cyclones, regions influenced by both front datasets are considered "Confirmed cold fronts", while areas influenced by only one method are considered "Unconfirmed cold fronts".

Figure 3 compares the frequency of Confirmed cold fronts to those identified using a single method. While confirmed fronts have a clear decrease in frequency from a maximum in the storm track to the south of Australia to a minimum in the tropics, those fronts identified by a single method show very different spatial structures. Fronts only identified by the TFP are most common along the coastline, particularly during the warm season and in the afternoon (not shown), potentially reflecting stationary temperature gradients between the land and ocean in these areas. In comparison, the WND method identifies a large frequency of fronts in northwestern Australia, particularly overnight, which may be detecting diurnal changes in wind direction associated with the sea breeze.

Figure 4 shows the average rainfall anomaly on front days compared to the mean rainfall across all days. In southern Australia (south of $25^{\circ} \mathrm{S}$ ), where cold fronts are more common, days where a cold front is identified using two different methods are more likely to produce rainfall than where a front is identified using only the TFP or only the WND method. While days with a Confirmed cold front tend to be wetter than average across the country, for most of southern Australia days where a cold front is identified by only one method are drier than the average across all days, and TFP-only fronts explain a smaller proportion of rainfall than expected from their frequency (Table 2). TFP fronts are particularly dry in parts of southwestern Australia, while WND-only fronts are particularly dry along the east coast.

In northern Australia cold fronts are typically not shown on Australian synoptic charts, and cold fronts are both less common and less important for total rainfall (Table 2). Interestingly, there are parts of the tropics where WNDonly fronts have relatively high likelihoods of producing at least $1 \mathrm{~mm}$ of rainfall (Fig. 4c). This suggests that, while the WND method was designed for the extratropics, it may be able to detect some sort of squall lines or other systems of relevance to tropical rainfall, noting that midlatitude troughs and fronts have been identified as contributing to the occurrence of monsoon bursts (Narsey et al. 2017). However, the low rainfall rates shown in Fig. 4a and the large differences between methods shown in Fig. 3 for the tropics highlight the fact that neither front method gives a useful indication of rainbearing systems in the tropics. Due to the lower skill of (a) MJJASO: Confirmed fronts

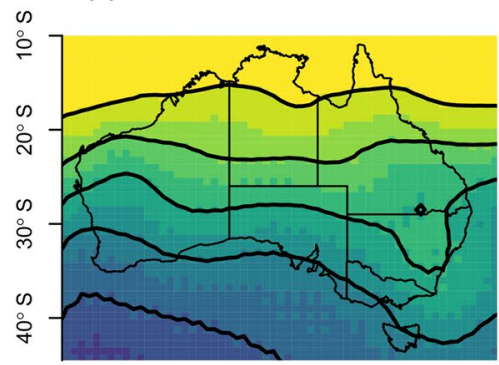

(d) NDJFMA: Confirmed fronts

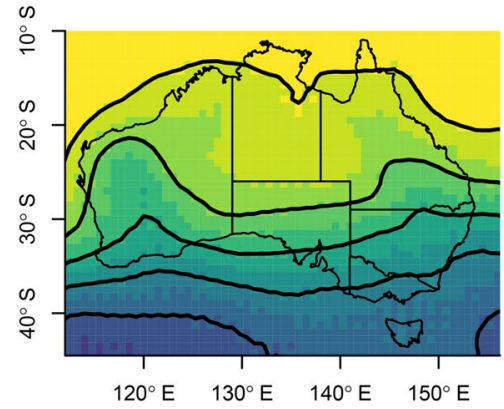

(b) MJJASO: Unconfirmed TFP fronts

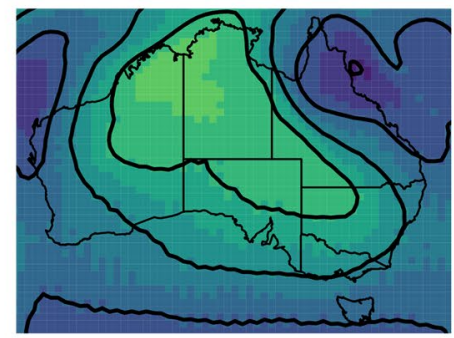

(e) NDJFMA: Unconfirmed TFP fronts

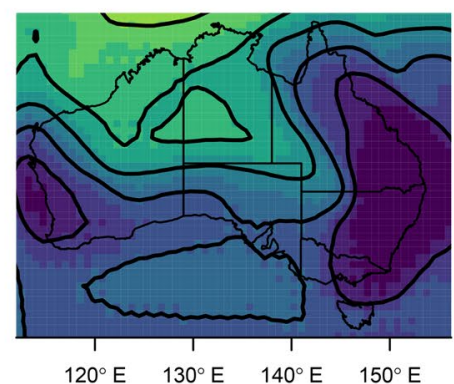

(c) MJJASO: Unconfirmed WND fronts
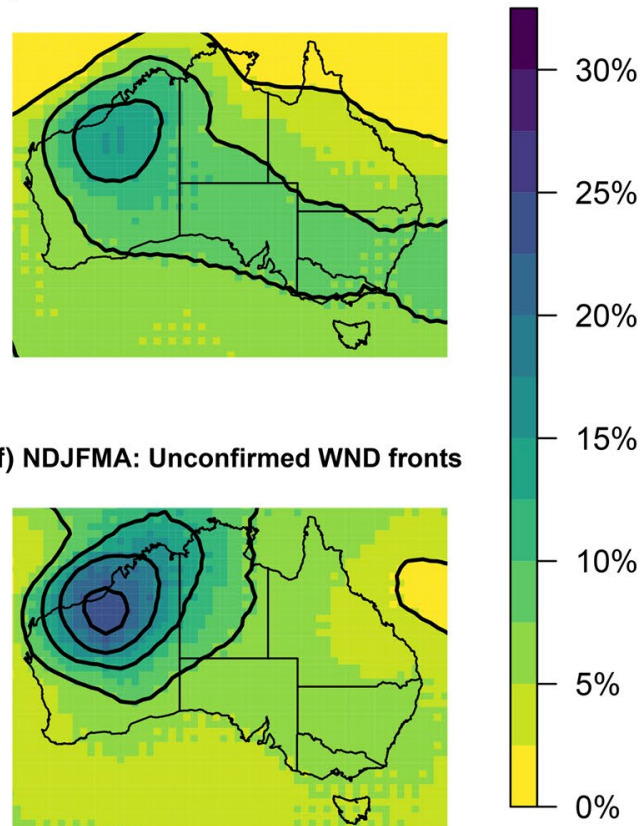

$120^{\circ} \mathrm{E} \quad 130^{\circ} \mathrm{E} \quad 140^{\circ} \mathrm{E} \quad 150^{\circ} \mathrm{E}$

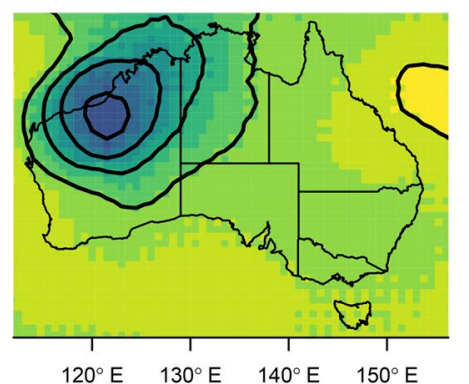

(f) NDJFMA: Unconfirmed WND fronts
Fig. 3 Percentage of hours influenced by a cold front, 1979-2015, in the cool season (May-October, top) and warm season (NovemberApril, bottom). (Left) confirmed cold fronts. (Middle) cold fronts identified using TFP but not WND. (Right) cold fronts identified using WND but not TFP. Solid contours every 5\% have $1^{\circ}$ of smoothing added, to balance the lower resolution of the WND data 
(a) Confirmed fronts

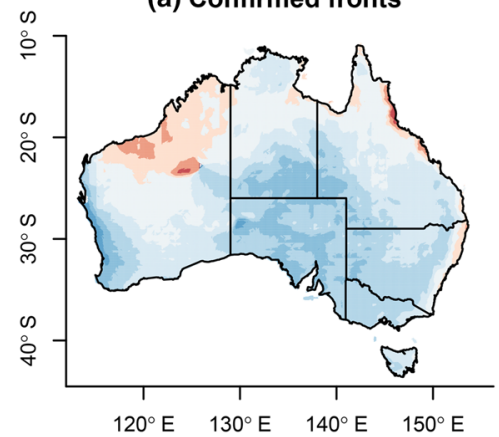

(b) Unconfirmed TFP fronts

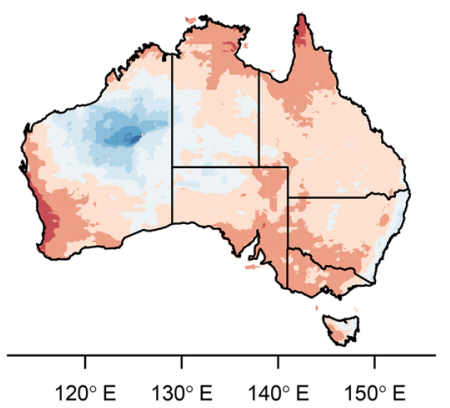

(c) Unconfirmed WND fronts

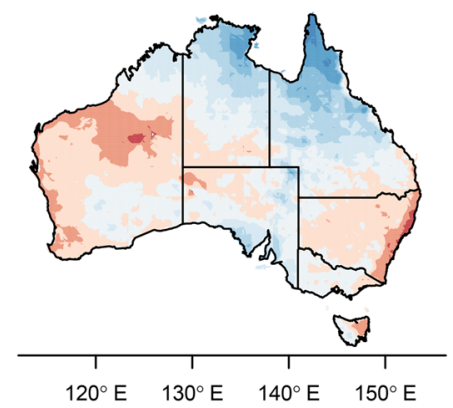

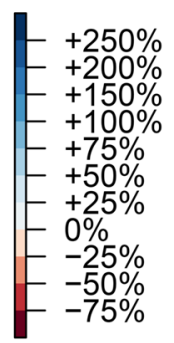

Fig. 4 Percentage difference between the average rainfall recorded on a day with a cold front, compared to the average daily rainfall across all days, 1979-2015. (Left) confirmed cold fronts. (Middle) cold fronts identified using TFP but not WND. (Right) cold fronts identified using WND but not TFP

front; this does not include fronts that may be connected to a distant low pressure system in the Southern Ocean.

The "Other" observations that are not classified as any of these seven rain-related weather types are then further subcategorised into.

1. High: observations where a high pressure centre was located within a $10^{\circ}$ radius, consistent with the region of dry conditions associated with Australian highs in Pepler et al. (2019a, b).

2. Warm front (WF): observations with a warm front present using the TFP dataset.

3. Unconfirmed events (Unconf): observations where a cyclone and/or cold front was present using one of the detection methods but not both.

4. Undefined events (Undef): remaining weather types.

In addition to the 6-hourly dataset, to compare the weather types dataset against daily gridded rainfall data we create a daily version of the dataset. For this version, each individual weather type is first aggregated across each day, so that a day which had a front at any of the 4 observations that day $(0000,0600,1200$ or 1800 UTC) is considered a front day. The classification process described above is then applied to the new daily dataset. This means that a day could be considered a "Cyclone + Front" day for a region if, for example, there was a cyclone detected at 0000UTC and a front detected at 1200UTC. Consequently, the frequency of combined event types is generally higher and the frequency of other and undefined events lower in the daily dataset (Fig. 5).

Compared to southern Australia, the weather types explain a smaller proportion of total observations in northern Australia, where cold fronts and anticyclones are uncommon and the majority of the year is dominated by prevailing easterly or westerly flow. In addition, Sects. 3.1 and 3.2 demonstrated that the cyclone and front 
Fig. 5 Percentage of observations of each weather system type in the $0.75^{\circ}$ ERA-Interim 6-hourly and daily analyses for Australia south of $25^{\circ} \mathrm{S}$, 1979-2015

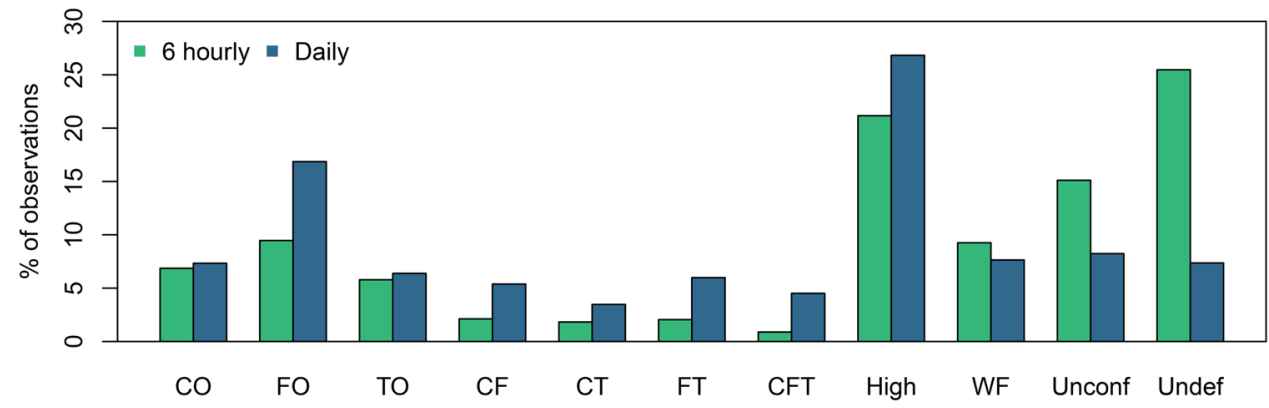

methods, designed for the midlatitudes, are less consistent in northern Australia. Consequently, results will focus on the region south of $25^{\circ} \mathrm{S}$ where the dataset is expected to be more applicable.

\subsection{Weather type rainfall}

To calculate the rainfall associated with each weather type, we use the daily version of the synoptic type database, which aggregates the weather types at the four observations 00001800UTC. The $0.75^{\circ}$ data is then converted to a $0 / 1$ flag for each weather type and bilinearly interpolated to the $0.05^{\circ}$ AWAP resolution, with values of 0.5 or higher used to indicate the presence of the type. Finally, the rainfall recorded at 9am local time on the subsequent day (equivalent to 22002300UTC in eastern Australia and 0100-0200 UTC in Western Australia) at each gridpoint in the AWAP analysis is attributed to the weather type present. Rain days are defined as experiencing $\geq 1 \mathrm{~mm}$ of rainfall, with additional thresholds of $10 \mathrm{~mm}$ and $25 \mathrm{~mm}$ used for moderate and heavy rain days.

For the 6-hourly rainfall from BARRA and station observations, rainfall is accumulated into four 6-hourly time periods each day (0000-0600, 0600-1200, 1200-1800 and 1800-0000UTC), with each rainfall observation compared to the weather types identified at both the initial and final observation, similar to the process used for daily rainfall data.

\section{Australian rainfall and weather types}

Averaged across southern Australia (south of $25^{\circ} \mathrm{S}$ ), $49 \%$ of all days at a given location fall into one of the seven main weather types (CO, FO, TO, CF, CT, FT, or CFT), with the remaining $51 \%$ of days classified into one of the four Other categories (Fig. 6). These seven weather types account for a higher proportion of rainfall, averaging $87 \%$ of all rain days across southern Australia and $91 \%$ of total rainfall. As shown in DC17, the combined types are disproportionately responsible for heavy rain days: the combination of a cyclone and thunderstorm occurs on $7 \%$ of days but $28 \%$ of days with at least $10 \mathrm{~mm}$ of rainfall, while a triple storm occurs on $4 \%$ of days but $16 \%$ of days with heavy rainfall. In comparison, days with just a cyclone or front without thunderstorm conditions are less likely to produce heavy rainfall.

The relative contribution of each weather type to total annual rainfall and rain days varies across the country (Fig. 7). While large areas of central Australia experience most of their rain from thunderstorm related systems (TO and CT) and relatively little rainfall from cyclones or fronts, the latter systems are important for rainfall in parts of the southwest and southeast (Fig. 7h, i). CO days are particularly

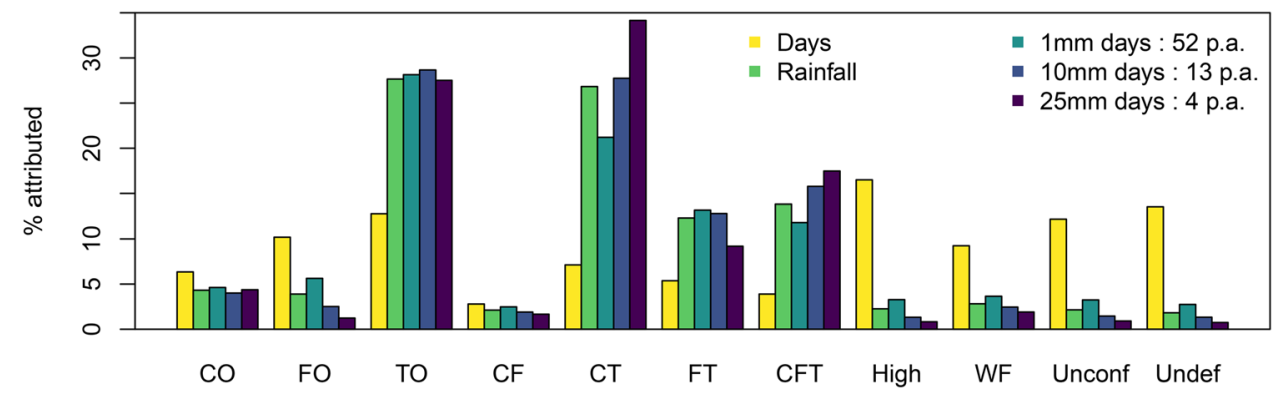

Fig. 6 Annual percentage contribution of each weather system type to rainfall in the $0.05^{\circ}$ AWAP gridded analyses between 1979 and 2015, averaged across all land areas of Australia south of $25^{\circ} \mathrm{S}$. Bars show the percentage of all days influenced by each weather type (days), the

total annual precipitation from each type (rainfall), and the proportion of all days with rainfall exceeding a given threshold $(1 \mathrm{~mm}, 10 \mathrm{~mm}$ and $25 \mathrm{~mm}$ ) that are associated with a given weather type. Legend shows the average number of days p.a. for each rainfall threshold 
(a) $\%$ days: $c 0$

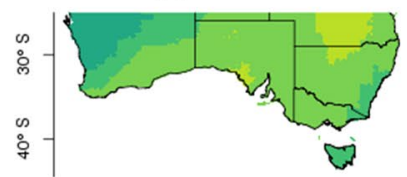

(b) $\%$ days : FO

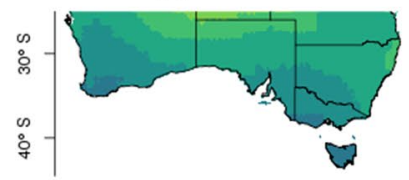

(c) \% days: to

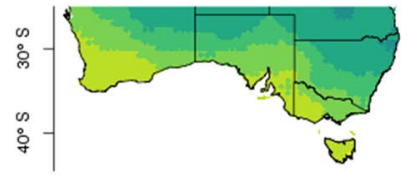

(d) \% days: CF

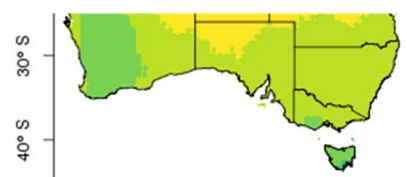

(e) \% days: CT

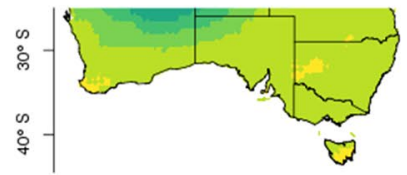

(f) \% days: FT

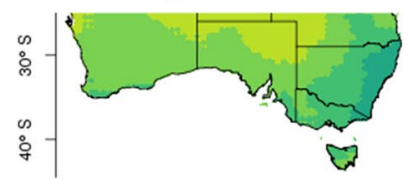

(g) \% days: CFT

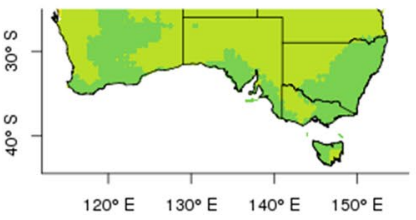

(n) $\%$ rain: CFT

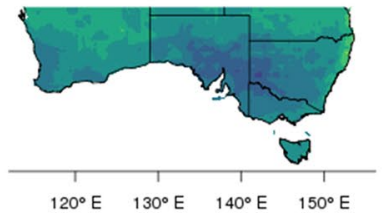

(o) $\% 1 \mathrm{~mm}$ days: $\mathrm{CO}$

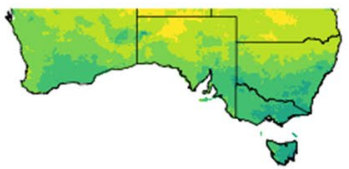

(p) $\% 1 \mathrm{~mm}$ days : FO

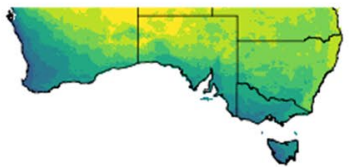

(q) $\% 1 \mathrm{~mm}$ days : TO

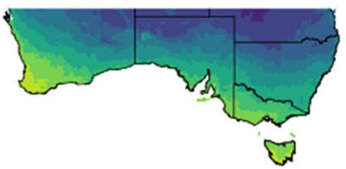

(r) $\% 1 \mathrm{~mm}$ days: CF

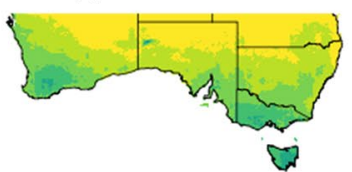

(s) $\% 1 \mathrm{~mm}$ days : CT

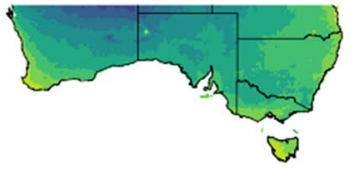

(t) $\% 1 \mathrm{~mm}$ days: FT

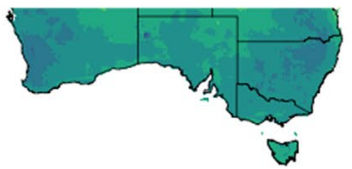

(u) $\% 1 \mathrm{~mm}$ days: CFT

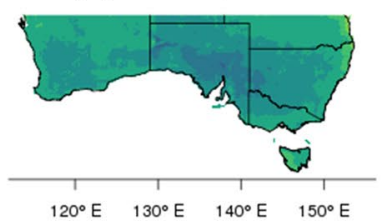

(v) $\% 10 \mathrm{~mm}$ days: $\mathrm{co}$

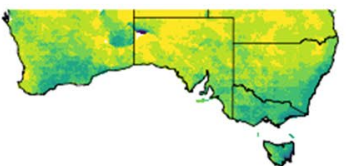

(w) $\% 10 \mathrm{~mm}$ days: FO

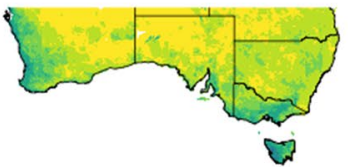

(x) $\% 10 \mathrm{~mm}$ days: TO

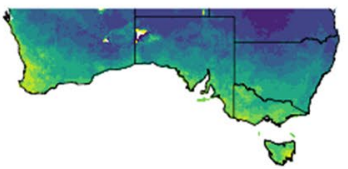

(y) $\% 10 \mathrm{~mm}$ days: CF

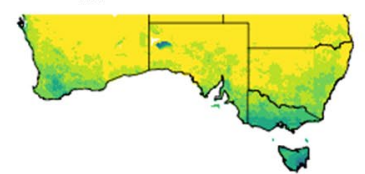

(z) $\% 10 \mathrm{~mm}$ days: CT

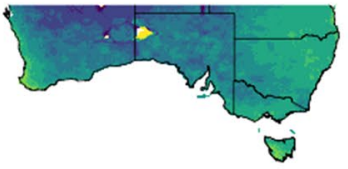

(aa) $\% 10 \mathrm{~mm}$ days: FT

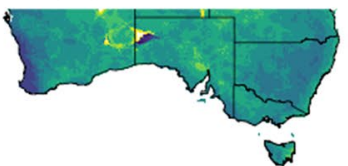

(ab) $\% 10 \mathrm{~mm}$ days: CFT

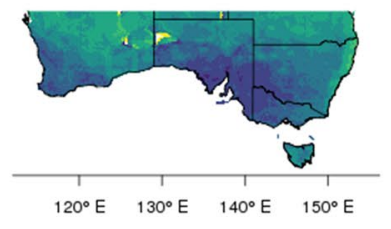

$\begin{array}{lllll}2.5 \% & 5 \% & 7.5 \% & 10 \% & 15 \%\end{array}$

Fig. 7 Annual percentage contribution of each of the 7 main weather types to (left column) all days, (column 2) total rainfall (mm), and days with (column 3 ) more than $1 \mathrm{~mm}$ and (right column) more than

important along parts of the southeast coast, where East Coast Lows cause a large proportion of annual rainfall and heavy rain events (Hopkins and Holland 1997; Pepler et al.

$10 \mathrm{~mm}$ of rain in the $0.05^{\circ}$ AWAP gridded analyses for southern Australia, 1979-2015. Note that the colour scale is not linear to allow easier interpretation at low values

2014a; Dowdy et al. 2019). Front-only days are also major contributors to both rain days and total rainfall in the key cropping areas of southwest Western Australia and southern 
Victoria, as noted in previous studies such as Pook et al. (2014).

The contributions of each weather type to rainfall vary throughout the year (Figs. 8, 9), with the proportion of southern Australian rainfall explained by the seven weather types ranging from $95 \%$ of summer (DJF) rainfall to $78 \%$ of winter (JJA) rainfall. $\mathrm{CO}$ and $\mathrm{FO}$ days are particularly important in southeastern Australia during the winter months (Fig. 9h, i), noting that front-only days may be linked to a cyclone south of Australia. Thunderstorm-related types are most important during the summer months, particularly for the cyclone and thunderstorm compound type (CT). Triple storms are particularly important for spring rain in southeastern Australia (Fig. 9u), with their area of influence shifting further southeast during summer as the main storm track moves poleward (Wernli and Schwierz 2006).

In addition to identifying the weather types that account for the majority of rainfall, we also wanted to identify the main weather systems present on "other" days, so that we can better understand how changes and variability in all types of weather systems influence total rainfall in Australia. High pressure systems, unconfirmed cyclones/fronts, and warm fronts collectively explain the majority of the remaining days, with high pressure systems and warm fronts each contributing more than 5\% of winter rainfall. After accounting for these additional systems, only $14 \%$ of days and less than $2 \%$ of annual rainfall remains undefined (Fig. 6), and 5\% of winter rainfall. These remaining days could potentially reflect a number of different synoptic patterns including zonal troughs that were not picked up by either the frontal scheme or thunderstorm environment datasets, or areas of interaction between cyclones and anticyclones.

Figure 10a-d shows the annual frequency of Other days separated by type. Undefined days are most common in the northern part of the region and especially in northern Australia (not shown), as this weather typing approach is not optimised for the tropics where the main weather types can be very different (Moron et al. 2019). Unconfirmed events and warm fronts are also more common in the north of the region, while high pressure systems are very common in the southern half of Australia where the subtropical ridge is located (Pepler et al. 2019b; Timbal and Drosdowsky 2013;
Rudeva et al. 2019). None of these types cause a large proportion of rainfall or rain days, with high pressure systems and warm fronts most important in coastal areas.

The eastern seaboard has frequently been identified as a distinct rainfall region in Australia, with very different patterns of rainfall variability and relationships with major climate drivers than elsewhere in southeast Australia (Timbal 2010; Pepler et al. 2014b; Rakich et al. 2008; Dowdy et al. 2015) and an increased frequency of extreme rainfall including from East Coast Lows (Dowdy et al. 2019). This region also emerges in this paper as a region where rainfall is less well explained by the seven weather types, with up to $10 \%$ of rainfall attributed to high pressure systems (Fig. 10i) as well as a relatively larger role from warm fronts and unconfirmed events. These may reflect the role of onshore easterly flow and weak coastal troughs in generating local showers and rainfall. The combined front dataset also appears to be less effective in this coastal area, with front-related types explaining a smaller proportion of rainfall (e.g. Figure 7n) compared to DC17. While this may truly reflect a tendency for fronts to rain out over the moderate elevations of the Great Dividing range, the WND-based front identification method may also be less able to identify fronts that develop in the prevailing easterly wind flow in this region, as well as the deformation of fronts by coastal topography e.g. during so-called "Southerly Busters" (Colquhoun et al. 1985).

As discussed in Sect. 3.3, when applied to sub-daily rainfall data the combined weather types form a smaller proportion of observations than they do when aggregated into daily data. However, the spatial patterns of rainfall attributed to each weather type are broadly consistent between the AWAP daily gridded analysis and both the 6-hourly BARRA reanalysis and the 6-hourly station observations. Averaged across southern Australia, 84\% of rainfall in BARRA falls in a 6-hourly period associated with one of the seven weather types, which is slightly below the $91 \%$ of rainfall attributed to these weather types using the daily AWAP data. At this higher temporal resolution, a larger proportion of rainfall from both BARRA and the weather stations is attributed to the $\mathrm{CO}$ and $\mathrm{FO}$ types, and a slightly lower proportion of rainfall is associated with combined weather types, particularly CT (Fig. 111). This difference is partially related to
Fig. 8 Contribution of each weather system type to total rainfall in the $0.05^{\circ} \mathrm{AWAP}$ gridded analyses for Australia south of $25^{\circ} \mathrm{S}, 1979-2015$ during austral autumn (MAM), winter (JJA), spring (SON) and summer (DJF)

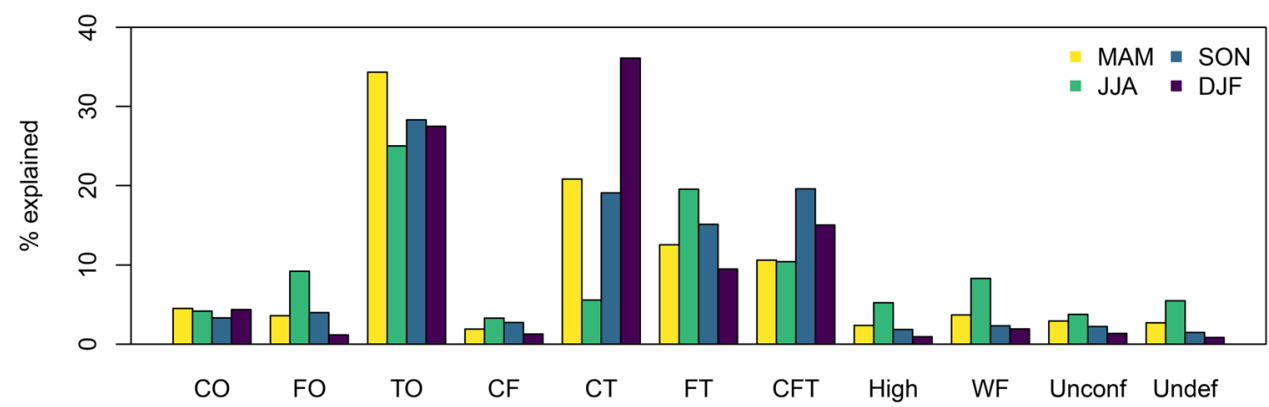


(a) MAM: CO

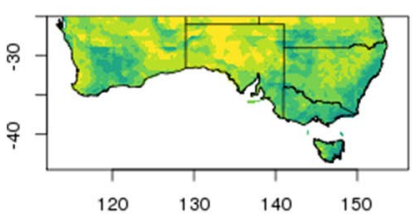

(b) MAM: FO

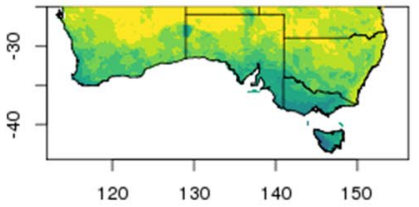

(c) MAM: TO

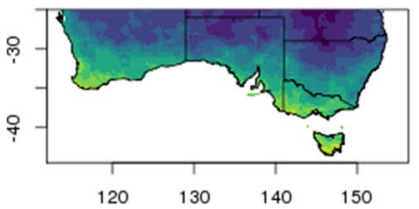

(d) MAM: CF

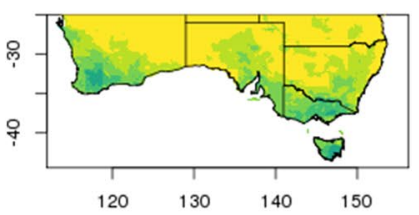

(e) MAM: CT

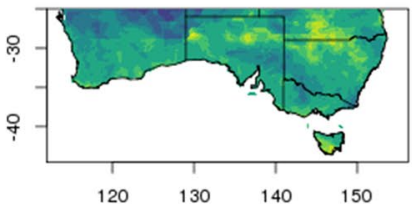

(f) MAM: FT

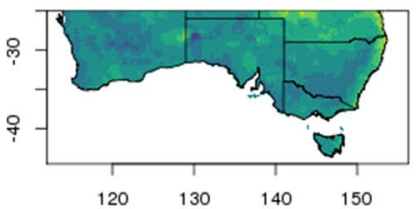

(g) MAM: CFT

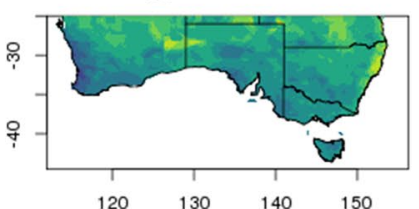

(h) JJA: Co

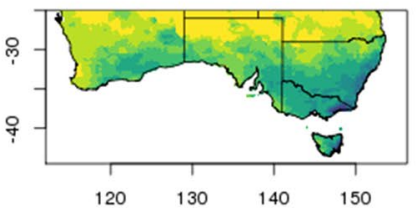

(i) JJA: FO

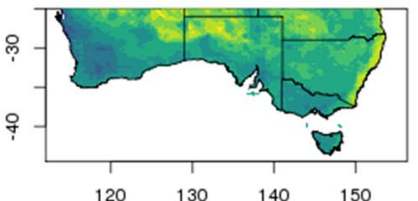

(j) JJA: TO

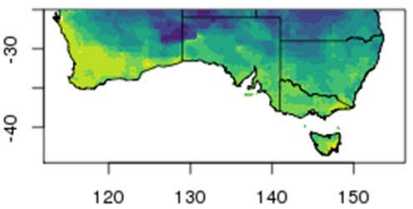

(k) JJA: CF

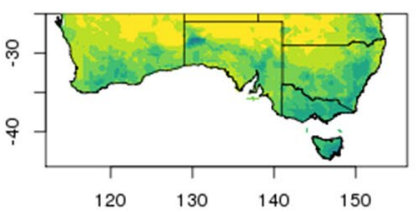

(I) JJA: CT

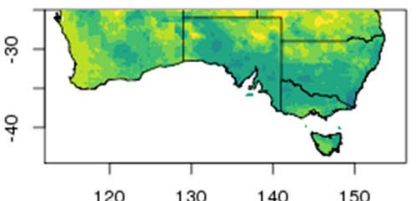

(m) JJA: FT

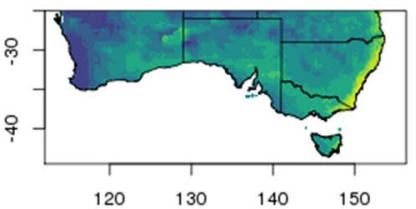

(n) JJA: CFT

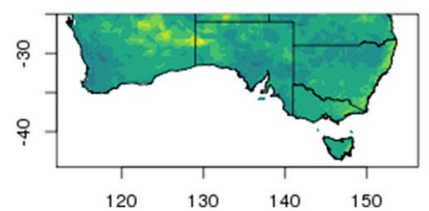

(o) SON: CO

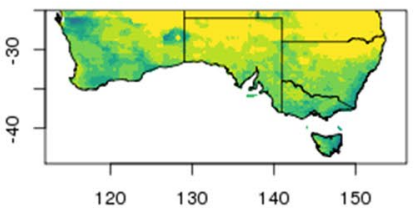

(p) SON: FO

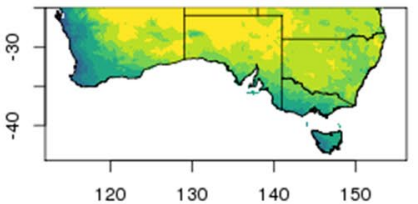

(q) SON: TO

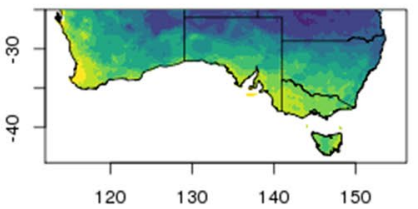

(r) SON: CF

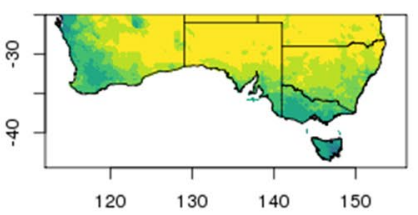

(s) SON: CT

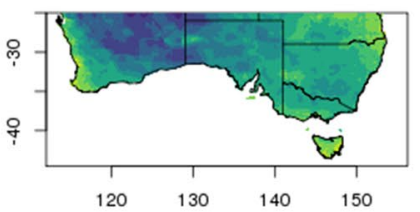

(t) SON: FT

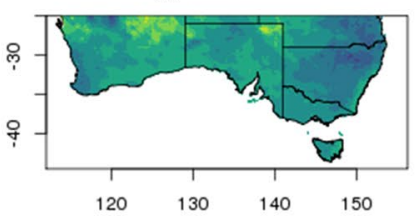

(u) SON: CFT

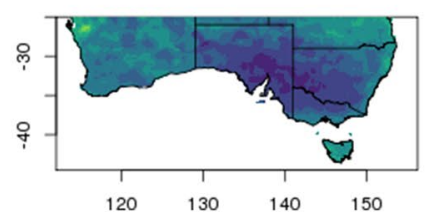

(v) DJF: Co

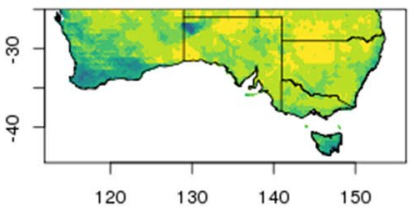

(w) DJF: Fo

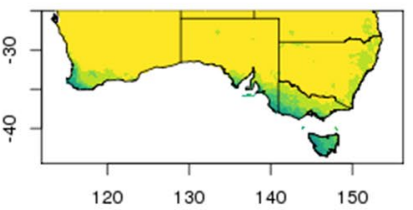

(x) DJF:TO

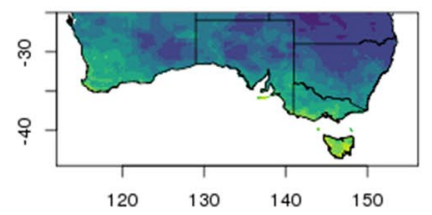

(y) DJF: CF

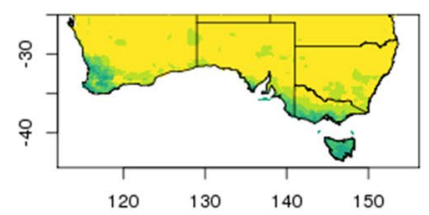

(z) DJF: CT

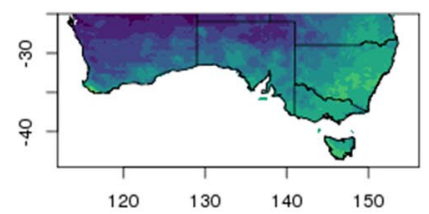

(aa) DJF : FT

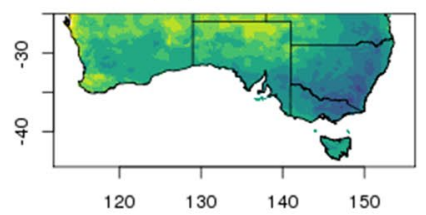

(ab) DJF: CFT

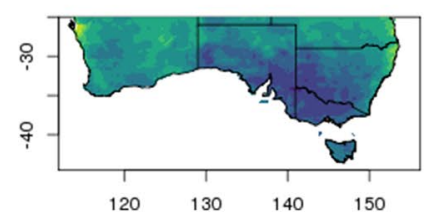

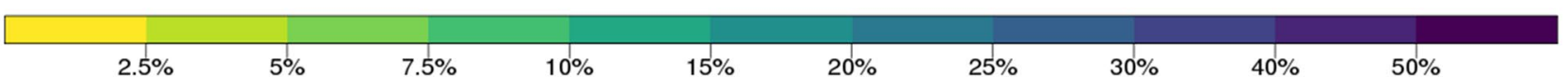

Fig. 9 Contribution of each of the 7 main weather types to total rainfall in the $0.05^{\circ}$ AWAP gridded analyses for southern Australia in each season, 1979-2015. Note that the colour scale is not linear to allow easier interpretation at low values

the lower frequencies of combined types in the hourly data (Fig. 5), but may also reflect changes in the relative frequency of cyclone-related types or their rain rates between the 1979-2015 period and the more recent 1990-2015 period for which BARRA is available (e.g. Risbey et al. 2013). 
(a) \% days: High

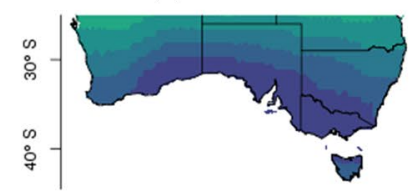

(b) \% days: WF

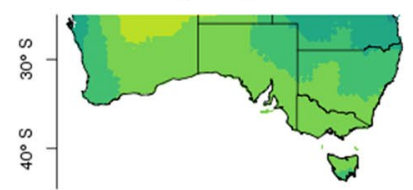

(c)\% days: Uncont

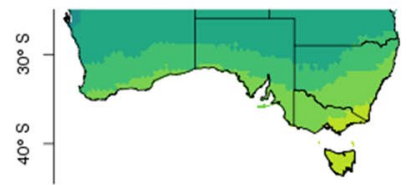

(d) \% days: Undefined

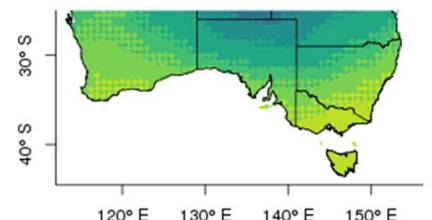

$120^{\circ} \mathrm{E} \quad 130^{\circ} \mathrm{E} \quad 140^{\circ} \mathrm{E} \quad 150^{\circ} \mathrm{E}$ (e) \% rain: High

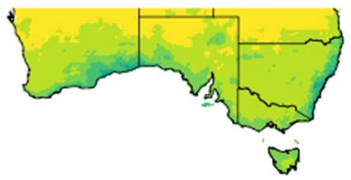

(f) \% rain: WF

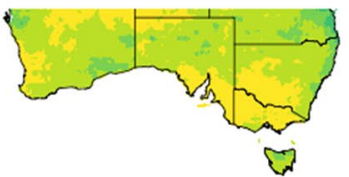

(g) \% rain: Uncont

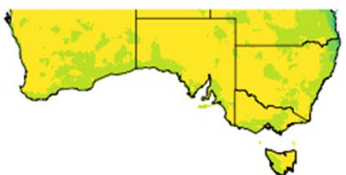

(h) \% rain: Undef

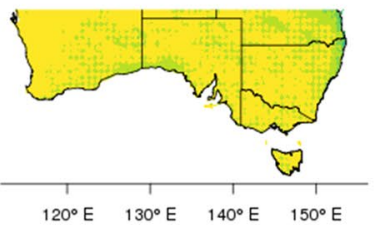

(i) $\% 1 \mathrm{~mm}$ days: High

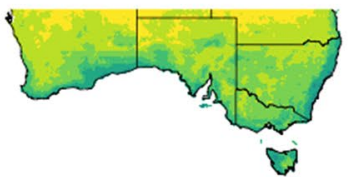

(j) $\% 1 \mathrm{~mm}$ days: WF

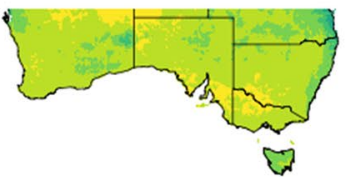

(k) $\% 1 \mathrm{~mm}$ days: Uncont

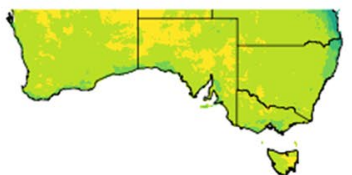

(j) $\% 1 \mathrm{~mm}$ days: Undef

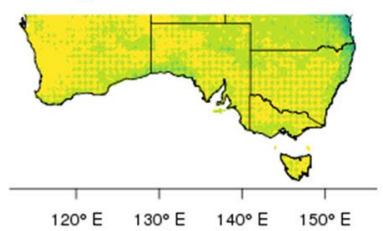

(m) $\% 10 \mathrm{~mm}$ days: High

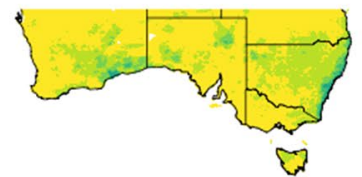

(n) $\% 10 \mathrm{~mm}$ days: WF

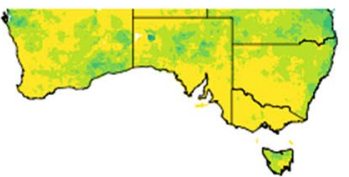

(o) $\% 10 \mathrm{~mm}$ days: Uncont

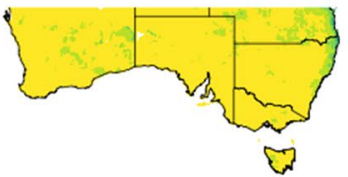

(p) $\% 10 \mathrm{~mm}$ days: Undef

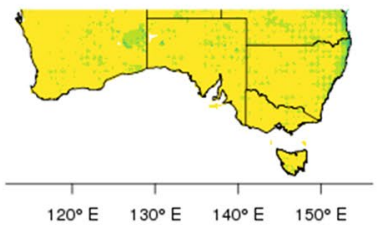

$40 \% \quad 50 \%$
Fig. 10 Contribution of the 3 other weather types and remaining undefined days to (left column) all days, (column 2) total rainfall $(\mathrm{mm})$, and days with (column 3 ) more than $1 \mathrm{~mm}$ and (right column)

\section{Discussion and conclusions}

In this paper we presented a new dataset of the main weather types influencing southern Australian rainfall. We built on previous work by DC17 to enhance the robustness of the cyclone and front datasets for this region of the world, as well as using a new thunderstorm environment dataset, enabling us to extend the compound event analysis to the 37 year period 1979-2015. We also added three additional weather types (high pressure systems, unconfirmed events and warm fronts), which collectively allowed us to systematically associate $86 \%$ of days and $98 \%$ of rainfall in southern Australia with weather systems.

In this paper, the weather type dataset has been combined with daily gridded rainfall analyses to demonstrate how the weather systems responsible for rainfall vary across southern Australia. Additionally, the base weather type dataset has a 6 hourly resolution, allowing it to be applied to a range of subdaily rainfall information including rain gauge data, satellite rainfall, and gridded reanalysis data, as was demonstrated
$10 \mathrm{~mm}$ of rain in the $0.05^{\circ}$ AWAP gridded analyses for southern Australia, 1979-2015. Note that the colour scale is not linear to allow easier interpretation at low values

here for a new high-resolution reanalysis dataset for Australia (Fig. 11).

Consistent with the results shown in DC17, while the combined weather types (CF, CT, FT, and CFT) are relatively infrequent they are very important for the most intense rainfall events. This is particularly true for the CT and CFT (triple storm) types which are responsible for four times as many $10 \mathrm{~mm}$ and $25 \mathrm{~mm}$ days than would be expected based on their average frequency. However, the different datasets used in this paper, particularly for fronts, result in differences in the overall spatial patterns of each weather system. This includes the east coast, where the frequency and importance of front-related types including CFT is lower than elsewhere in southeast Australia, in contrast to DC17 who identified the east coast as a region where CFT events are particularly important for rainfall extremes. This may indicate rainfall associated with easterly wind regimes which is less well characterised by this weather types dataset, as well as larger discrepancies in front identification between the two methods on the east coast than elsewhere in southern Australia. 
(a) \% AWAP rain: co

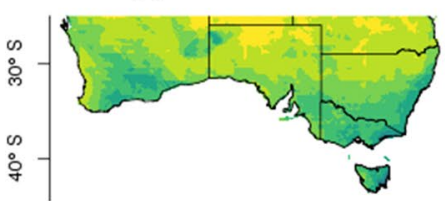

(b) \% AWAP rain: FO

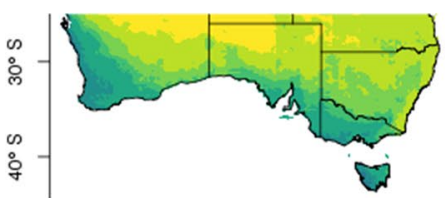

(c) \% AWAP rain: TO

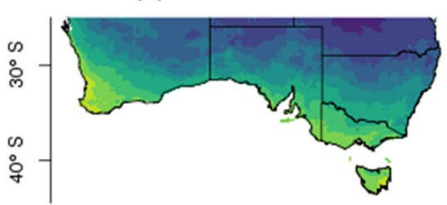

(d) \% AWAP rain: CF

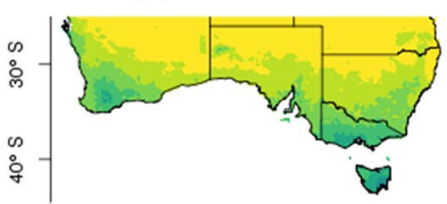

(e) \% AWAP rain: CT

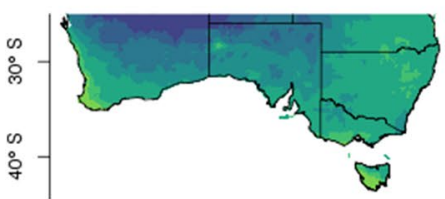

(f) \% AWAP rain: FT

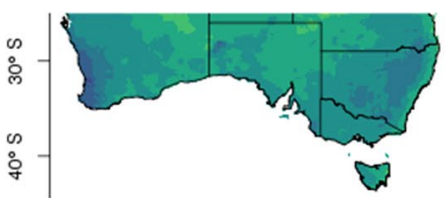

(g) \% AWAP rain: CFT

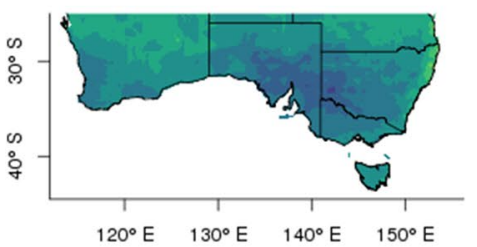

(h) \% BARRA rain: co

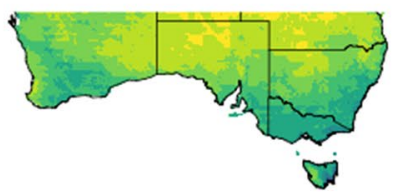

(i) \% BARRA rain: Fo

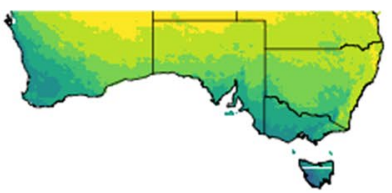

(j) \% BARRA rain: to

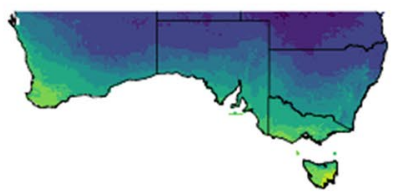

(k) \% BARRA rain: CF

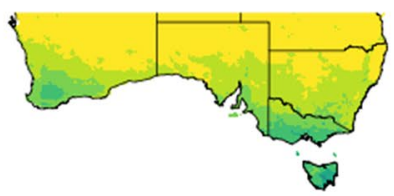

(I) \% BARRA rain: CT

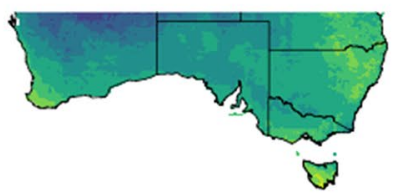

(m) \% BARRA rain: FT

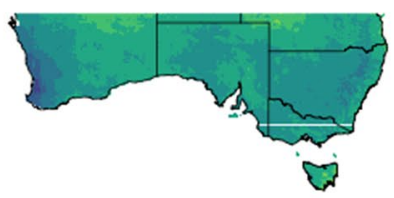

(n) \% BARRA rain: CFT

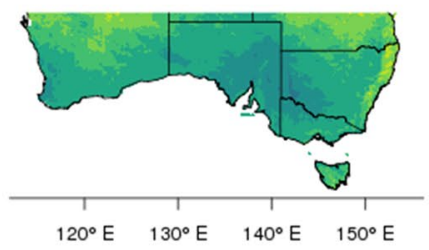

(o) \% Station rain: co

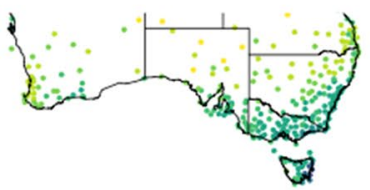

(p) \% Station rain: FO

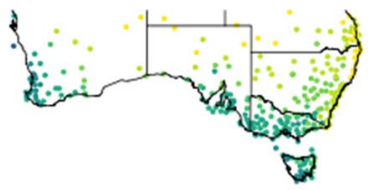

(q) \% Station rain: To

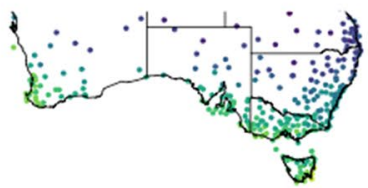

(r) \% Station rain: CF

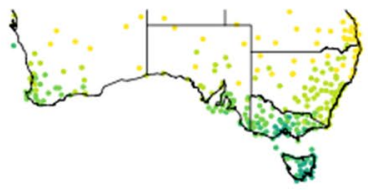

(s) \% Station rain: CT

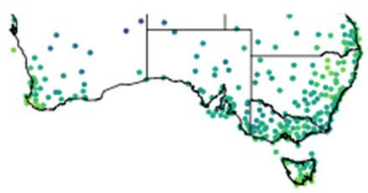

(t) \% Station rain: FT

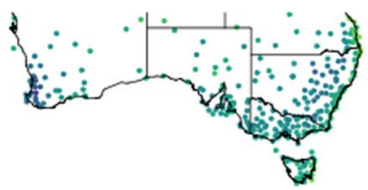

(u) \% Station rain: CFT

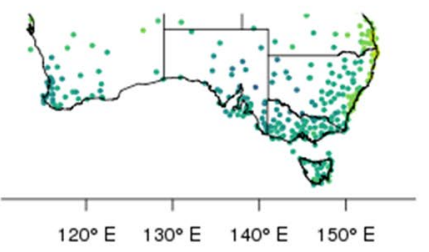

$\begin{array}{llllllllll}2.5 \% & 5 \% & 7.5 \% & 10 \% & 15 \% & 20 \% & 25 \% & 30 \% & 40 \% & 50 \%\end{array}$ 
4Fig. 11 Contribution of each of the 7 main weather types to total rainfall in southern Australia. (Left) the $0.05^{\circ}$ AWAP gridded daily rainfall data, 1979-2015. (Centre) the $0.12^{\circ}$ BARRA reanalysis 6-hourly rainfall data, 1990-2015. (Right) 6-hourly gauge rainfall for all Bureau of Meteorology gauges with at least 10 years of hourly data between 1979 and 2015. Note that the colour scale is not linear to allow easier interpretation at low values

The relative contribution of cyclones to rainfall in southern Australia is lower than observed in many other studies for other parts of the globe (Hawcroft et al. 2012; Pfahl and Wernli 2012). This reflects the subtropical location of our area of interest, which is to the north of the main Southern Hemisphere storm tracks. Consequently this area experiences a mixture of both extratropical systems such as cut-off lows and mobile fronts embedded in the midlatitude westerlies, particularly during the winter months, and more tropical influences such as prevailing easterly winds, thunderstorms and sometimes decaying or transitioning tropical cyclones during the summer months.

The length of the dataset produced here will allow a better understanding of how the frequency of each weather type and its associated rainfall may be differently influenced by both key climate drivers such as the El Niño-Southern Oscillation and Southern Annular Mode and long-term trends. This will enable future work to better understand the roles of different weather systems and their interactions in southern Australia's rainfall variability by season including recent cool-season rainfall declines (Murphy and Timbal 2008; Risbey et al. 2013; Rauniyar et al. 2019).

Acknowledgements The authors thank Luke Osburn, Blair Trewin, Michael Pook and two anonymous reviewers for their helpful comments on the manuscript.

Funding This project is funded by the Victorian Department of Environment, Land, Water and Planning with support from the Earth Systems and Climate Change Hub of the Australian Government's National Environmental Science Programme, and was assisted by resources from the Australian National Computational Infrastructure (NCI).

\section{Compliance with ethical standards}

Conflict of interest The authors declare that they have no conflict of interest.

Code availability The datasets presented in this paper are based on a number of pieces of software for identifying and tracking cyclones and fronts, which are available by contacting the authors of the papers cited in the Methods section. Additional analysis and figures were performed using the R and NCL programming languages.

Availability of data The ERA-Interim reanalysis is available from the ECMWF at https://apps.ecmwf.int/datasets/data/interim-full-invariant/, and Australian gauge and gridded rainfall datasets and the BARRA reanalysis are available from the Australian Bureau of Meteorology. The derived storm type dataset is available for research use by contacting the authors, and will be shared for research purposes as an output of the Victorian Water and Climate Initiative.

Open Access This article is licensed under a Creative Commons Attribution 4.0 International License, which permits use, sharing, adaptation, distribution and reproduction in any medium or format, as long as you give appropriate credit to the original author(s) and the source, provide a link to the Creative Commons licence, and indicate if changes were made. The images or other third party material in this article are included in the article's Creative Commons licence, unless indicated otherwise in a credit line to the material. If material is not included in the article's Creative Commons licence and your intended use is not permitted by statutory regulation or exceeds the permitted use, you will need to obtain permission directly from the copyright holder. To view a copy of this licence, visit http://creativecommons.org/licenses/by/4.0/.

\section{References}

Acharya SC, Nathan R, Wang QJ, Su CH, Eizenberg N (2019) An evaluation of daily precipitation from a regional atmospheric reanalysis over Australia. Hydrol Earth Syst Sci 23:3387-3403. https ://doi.org/10.5194/hess-23-3387-2019

Alexander LV, Bador M, Roca R, Contractor S, Donat M, Nguyen PL (2020) Intercomparison of annual precipitation indices and extremes over global land areas from in situ, space-based and reanalysis products. Environ Res Lett. https://doi.org/10.1088/17489326/ab79e2

Allen JT, Karoly DJ (2014) A climatology of Australian severe thunderstorm environments 1979-2011: inter-annual variability and ENSO influence. Int J Climatol 34:81-97. https://doi.org/10.1002/ joc. 3667

Allen JT, Karoly DJ, Pezza AB, Black MT (2010) Explosive cyclogenesis: a global climatology comparing multiple reanalyses. J Clim 23:6468-6484. https://doi.org/10.1175/2010JCLI3437.1

Berry G, Reeder MJ, Jakob C (2011) A global climatology of atmospheric fronts. Geophys Res Lett 38:L04809. https://doi. org/10.1029/2010GL046451

Bitsa E, Flocas H, Kouroutzoglou J, Hatzaki M, Rudeva I, Simmonds I (2019) Development of a front identification scheme for compiling a cold front climatology of the Mediterranean. Climate 7:130. https://doi.org/10.3390/cli7110130

Blázquez J, Solman SA (2017) Fronts and precipitation in CMIP5 models for the austral winter of the Southern Hemisphere. Clim Dyn 50:2705. https://doi.org/10.1007/s00382-017-3765-z

Brooks HE, Lee JW, Craven JP (2003) The spatial distribution of severe thunderstorm and tornado environments from global reanalysis data. Atmos Res 67-68:73-94. https://doi.org/10.1016/S0169 -8095(03)00045-0

Cao Z, Xu Q, Zhang DL (2019) A new method to diagnose cyclonecyclone interaction and its influences on precipitation. J Appl Meteorol Climatol 58:1821-1851. https://doi.org/10.1175/ JAMC-D-18-0344.1

Catto JL, Pfahl S (2013) The importance of fronts for extreme precipitation. J Geophys Res Atmos 118:10791-10801. https://doi. org/10.1002/jgrd.50852

Catto JL, Pfahl S, Jakob C, Berry G, Nicholls N (2012) Relating global precipitation to atmospheric fronts. Geophys Res Lett 39:L10805. https://doi.org/10.1029/2012GL051736

Catto JL, Madonna E, Joos H, Rudeva I, Simmonds I (2015) Global relationship between fronts and warm conveyor belts and the impact on extreme precipitation. J Clim 28:8411-8429. https:// doi.org/10.1175/JCLI-D-15-0171.1 
Colquhoun JR, Shepherd DJ, Coulman CE, Smith RK, McInnes K (1985) The southerly burster of south eastern Australia: an orographically forced cold front. Mon Weather Rev 113:2090-2107. https://doi.org/10.1175/1520-0493(1985)113<2090:TSBOS $\mathrm{E}>2.0 . \mathrm{CO} ; 2$

Copernicus Climate Change Service (C3S) (2017) ERA5: fifth generation of ECMWF atmospheric reanalyses of the global climate. Copernicus Clim Chang Serv Clim Data Store. https://cds.clima te.copernicus.eu/cdsapp\#!/home. Accessed Mar 2020

Cummins KL, Murphy MJ (2009) An overview of lightning locating systems: history, techniques, and data uses, with an in-depth look at the U.S NLDN. IEEE Trans Electromagn Compat 51:499-518. https://doi.org/10.1109/TEMC.2009.2023450

Dare RA, Davidson NE, Mcbride JL (2012) Tropical cyclone contribution to rainfall over australia. Mon Weather Rev 140:3606-3619. https://doi.org/10.1175/MWR-D-11-00340.1

Dee DP et al (2011) The ERA-Interim reanalysis: configuration and performance of the data assimilation system. Q J R Meteorol Soc 137:553-597. https://doi.org/10.1002/qj.828

Di Luca A, Evans JP, Pepler A, Alexander L, Argüeso D (2015) Resolution sensitivity of cyclone climatology over Eastern Australia using six reanalysis products. J Clim 28:9530-9549. https://doi. org/10.1175/JCLI-D-14-00645.1

Dowdy AJ (2020) Climatology of thunderstorms, convective rainfall and dry lightning environments in Australia. Clim Dyn. https:// doi.org/10.1007/s00382-020-05167-9

Dowdy AJ, Catto JL (2017) Extreme weather caused by concurrent cyclone, front and thunderstorm occurrences. Sci Rep 7:srep40359. https://doi.org/10.1038/srep40359

Dowdy AJ, Mills GA, Timbal B (2011) Large-scale indicators of Australian East Coast Lows and associated extreme weather events. Centre for Australian Weather and Climate Research Technical Report 37, p 92, available from: http://www.cawcr.gov.au/ publications

Dowdy AJ, Grose MR, Timbal B, Moise A, Ekstrom M, Bhend J, Wilson L (2015) Rainfall in Australia's eastern seaboard: a review of confidence in projections based on observations and physical processes. Aust Meteorol Oceanogr J 65:107-126. https://doi. org/10.22499/2.6501.008

Dowdy AJ et al (2019) Review of Australian east coast low pressure systems and associated extremes. Clim Dyn 53:4887. https://doi. org/10.1007/s00382-019-04836-8

Hawcroft MK, Shaffrey LC, Hodges KI, Dacre HF (2012) How much Northern Hemisphere precipitation is associated with extratropical cyclones? Geophys Res Lett 39:L24809. https://doi. org/10.1029/2012GL053866

Hodges KI, Lee RW, Bengtsson L (2011) A comparison of extratropical cyclones in recent reanalyses ERA-Interim, NASA MERRA, NCEP CFSR, and JRA-25. J Clim 24:4888-4906. https://doi. org/10.1175/2011JCLI4097.1

Hope PK, Drosdowsky W, Nicholls N (2006) Shifts in the synoptic systems influencing southwest Western Australia. Clim Dyn 26:751-764. https://doi.org/10.1007/s00382-006-0115-y

Hope $\mathrm{P}$ et al (2014) A comparison of automated methods of front recognition for climate studies: a case study in Southwest Western Australia. Mon Weather Rev 142:343-363. https://doi. org/10.1175/MWR-D-12-00252.1

Hope $\mathrm{P}$ et al (2015) Seasonal and regional signature of the projected southern Australian rainfall reduction. Aust Meteorol Oceanogr J 65:54-71. https://doi.org/10.22499/2.6501.005

Hopkins LC, Holland GJ (1997) Australian heavy-rain days and associated east coast cyclones: 1958-92. J Clim 10:621-634. https://doi. org/10.1175/1520-0442(1997)010<0621:AHRDAA > 2.0.CO;2

Hutchins ML, Holzworth RH, Virts KS, Wallace JM, Heckman S (2013) Radiated VLF energy differences of land and oceanic lightning. Geophys Res Lett 40:2390-2394. https://doi. org/10.1002/grl.50406

Jones DA, Simmonds I (1993) A climatology of southern-hemisphere extratropical cyclones. Clim Dyn 9:131-145. https://doi. org/10.1007/BF00209750

Jones DA, Wang W, Fawcett R (2009) High-quality spatial climate data-sets for Australia. Aust Meteorol Oceanogr J 58:233-248

Kepert JD, Smith RK (1992) A simple model of the Australian west coast trough. Mon Weather Rev 120:2042-2055. https://doi. org/10.1175/1520-0493(1992)120<2042:ASMOTA > 2.0.CO;2

Lavender SL, Abbs DJ (2013) Trends in Australian rainfall: contribution of tropical cyclones and closed lows. Clim Dyn 40:317-326. https://doi.org/10.1007/s00382-012-1566-y

Liu P et al (2017) Climatology of tracked persistent maxima of 500hPa geopotential height. Clim Dyn. https://doi.org/10.1007/ s00382-017-3950-0

Moron V, Barbero R, Evans JP, Westra S, Fowler HJ (2019) Weather types and hourly to multiday rainfall characteristics in tropical Australia. J Clim 32:3983-4011. https://doi.org/10.1175/ JCLI-D-18-0384.1

Murphy BF, Timbal B (2008) A review of recent climate variability and climate change in southeastern Australia. Int J Climatol 28:859-879. https://doi.org/10.1002/joc.1627

Murray RJ, Simmonds I (1991) A numerical scheme for tracking cyclone centres from digital data. Part I: development and operation of the scheme. Aust Meteorol Mag 39:155-166

Narsey S, Reeder MJ, Ackerley D, Jakob C (2017) A midlatitude influence on Australian monsoon bursts. J Clim 30:5377-5393. https://doi.org/10.1175/JCLI-D-16-0686.1

Neu U et al (2013) Imilast: A community effort to intercompare extratropical cyclone detection and tracking algorithms. Bull Am Meteorol Soc 94:529-547. https://doi.org/10.1175/BAMSD-11-00154.1

Ng B, Walsh K, Lavender S (2015) The contribution of tropical cyclones to rainfall in northwest Australia. Int J Climatol 35:2689-2697. https://doi.org/10.1002/joc.4148

Papritz L, Pfahl S, Rudeva I, Simmonds I, Sodemann H, Wernli H (2014) The role of extratropical cyclones and fronts for southern ocean freshwater fluxes. J Clim 27:6205-6224. https://doi. org/10.1175/JCLI-D-13-00409.1

Pepler A, Dowdy A (2020) A three-dimensional perspective on extratropical cyclone impacts. J Clim. https://doi.org/10.1175/ JCLI-D-19-0445.1

Pepler A, Dowdy A, Coutts-Smith A, Timbal B (2014a) The role of east coast lows on rainfall patterns and inter-annual variability across the east coast of Australia. Int J Climatol 34:1011-1021. https://doi.org/10.1002/joc.3741

Pepler A, Timbal B, Rakich C, Coutts-Smith A (2014b) Indian ocean dipole overrides ENSO's influence on cool season rainfall across the Eastern seaboard of Australia. J Clim 27:3816-3826. https://doi.org/10.1175/JCLI-D-13-00554.1

Pepler AS, Di Luca A, Ji F, Alexander LV, Evans JP, Sherwood SC (2015) Impact of identification method on the inferred characteristics and variability of Australian east coast lows. Mon Weather Rev 143:864-877. https://doi.org/10.1175/MWR-D14-00188.1

Pepler AS, Di Luca A, Evans JP (2018) Independently assessing the representation of midlatitude cyclones in high-resolution reanalyses using satellite observed winds. Int J Climatol 38:1314-1327. https://doi.org/10.1002/joc.5245

Pepler A, Dowdy A, Hope P (2019a) A global climatology of surface anticyclones, their variability, associated drivers and longterm trends. Clim Dyn 52:5397. https://doi.org/10.1007/s0038 2-018-4451-5 
Pepler A, Dowdy A, Hope P, Hope P, Dowdy A (2019b) Long-term changes in southern Australian anticyclones and their impacts. Clim Dyn 53:4701. https://doi.org/10.1007/s00382-019-04819-9

Pfahl S, Wernli H (2012) Quantifying the relevance of cyclones for precipitation extremes. J Clim 25:6770-6780. https://doi. org/10.1175/JCLI-D-11-00705.1

Pook MJ, Risbey JS, McIntosh PC (2011) The synoptic climatology of cool-season rainfall in the central wheatbelt of Western Australia. Mon Weather Rev 140:28-43. https://doi.org/10.1175/MWR-D11-00048.1

Pook MJ, Risbey JS, McIntosh PC, Ummenhofer CC, Marshall AG, Meyers GA (2013) The seasonal cycle of blocking and associated physical mechanisms in the Australian region and relationship with rainfall. Mon Weather Rev 141:4534-4553. https://doi. org/10.1175/MWR-D-13-00040.1

Pook MJ, Risbey JS, McIntosh PC (2014) A comparative synoptic climatology of cool-season rainfall in major grain-growing regions of southern Australia. Theor Appl Climatol 117:521-533. https ://doi.org/10.1007/s00704-013-1021-y

Qi L, Leslie LM, Speer MS (2006) Climatology of cyclones over the southwest Pacific: 1992-2001. Meteorol Atmos Phys 91:201-209. https://doi.org/10.1007/s11427-006-0201-8

Rakich CS, Holbrook NJ, Timbal B (2008) A pressure gradient metric capturing planetary-scale influences on eastern Australian rainfall. Geophys Res Lett. https://doi.org/10.1029/2007GL032970

Rauniyar SP, Power SB, Hope P (2019) A literature review of past and projected changes in Victorian rainfall and their causes, and climate baselines. Bur Res Rep 37:42

Raut BA, Reeder MJ, Jakob C (2017) Trends in CMIP5 rainfall patterns over southwestern Australia. J Clim 30:1779-1788. https://doi. org/10.1175/JCLI-D-16-0584.1

Rehman SU, Khan K, Simmonds I (2019) Links between Tasmanian precipitation variability and the Indian Ocean subtropical high. Theor Appl Climatol. https://doi.org/10.1007/s00704-019-02891 $-\mathrm{Z}$

Reid KJ, Simmonds I, Vincent CL, King AD (2019) The Australian Northwest cloudband: climatology, mechanisms and association with precipitation. J Clim 32:1-48. https://doi.org/10.1175/ jcli-d-19-0031.1

Risbey JS, Mcintosh PC, Pook MJ (2013) Synoptic components of rainfall variability and trends in southeast Australia. Int J Climatol 33:2459-2472. https://doi.org/10.1002/joc.3597

Rudeva I, Simmonds I (2015) Variability and trends of global atmospheric frontal activity and links with large-scale modes of variability. J Clim 28:3311-3330. https://doi.org/10.1175/JCLID-14-00458.1

Rudeva I, Simmonds I, Crock D, Boschat G (2019) Midlatitude fronts and variability in the Southern Hemisphere tropical width. J Clim 32:8243-8260. https://doi.org/10.1175/JCLI-D-18-0782.1

Schemm S, Rudeva I, Simmonds I (2015) Extratropical fronts in the lower troposphere-global perspectives obtained from two automated methods. Q J R Meteorol Soc 141:1686-1698. https://doi. org/10.1002/qj.2471

Simmonds I, Keay K (2000) Mean southern hemisphere extratropical cyclone behavior in the 40-year NCEP-NCAR reanalysis. J Clim 13:873-885. https://doi.org/10.1175/15200442(2000)013<0873:MSHECB > 2.0.CO;2

Simmonds I, Murray RJ, Leighton RM (1999) A refinement of cyclone tracking methods with data from FROST. Aust Meteorol Mag Spec Ed 35-49

Simmonds I, Keay K, Bye JAT (2012) Identification and climatology of Southern Hemisphere mobile fronts in a modern reanalysis. J Clim 25:1945-1962. https://doi.org/10.1175/JCLI-D-11-00100.1

Sturman A, Tapper NJ (1996) The weather and climate of Australia and New Zealand. Oxford University Press, Oxford

Su CH et al (2019) BARRA v1.0: the Bureau of Meteorology Atmospheric high-resolution Regional Reanalysis for Australia. Geosci Model Dev 12:2049-2068. https://doi.org/10.5194/ gmd-12-2049-2019

Thomas CM, Schultz DM (2019a) What are the best thermodynamic quantity and function to define a front in gridded model output? Bull Am Meteorol Soc 100:873-896. https://doi.org/10.1175/ bams-d-18-0137.1

Thomas CM, Schultz DM (2019b) Global climatologies of fronts, airmass boundaries, and airstream boundaries: why the definition of "Front" Matters. Mon Weather Rev 147:691-717. https://doi. org/10.1175/mwr-d-18-0289.1

Tilinina N, Gulev SK, Rudeva I, Koltermann P (2013) Comparing cyclone life cycle characteristics and their interannual variability in different reanalyses. J Clim 26:6419-6438. https://doi. org/10.1175/JCLI-D-12-00777.1

Timbal B (2010) The climate of the Eastern Seaboard of Australia: a challenging entity now and for future projections. IOP Conf Ser Earth Environ Sci 11:12013. https://doi.org/10.1088/17551315/11/1/012013

Timbal B, Drosdowsky W (2013) The relationship between the decline of Southeastern Australian rainfall and the strengthening of the subtropical ridge. Int J Climatol 33:1021-1034. https://doi. org/10.1002/joc.3492

Verdon-Kidd DC, Kiem AS (2009) On the relationship between largescale climate modes and regional synoptic patterns that drive Victorian rainfall. Hydrol Earth Syst Sci 13:467-479. https://doi. org/10.5194/hess-13-467-2009

Virts KS, Wallace JM, Hutchins ML, Holzworth RH, Virts KS, Wallace JM, Hutchins ML, Holzworth RH (2013) Highlights of a new ground-based, hourly global lightning climatology. Bull Am Meteorol Soc 94:1381-1391. https://doi.org/10.1175/BAMSD-12-00082.1

Wernli H, Schwierz C (2006) Surface cyclones in the ERA-40 Dataset (1958-2001). Part I: novel identification method and global climatology. J Atmos Sci 63:2486-2507. https://doi.org/10.1175/ JAS3766.1

Wright WJ (1989) A synoptic climatological classification of winter precipitation in Victoria. Aust Meteorol Mag 37:217-229

Publisher's Note Springer Nature remains neutral with regard to jurisdictional claims in published maps and institutional affiliations. 